\title{
Nanomedicine-based antimicrobial peptide delivery for bacterial infections: recent advances and future prospects
}

\author{
Raj Kumar Thapa ${ }^{1} \cdot$ Dzung B. Diep ${ }^{2} \cdot$ Hanne Hjorth Tønnesen ${ }^{1}$
}

Received: 21 December 2020 / Accepted: 22 March 2021 / Published online: 1 April 2021

(c) The Author(s) 2021

\begin{abstract}
Background Antimicrobial peptides (AMPs) have gained wide interest as viable alternatives to antibiotics owing to their potent antimicrobial effects and the low propensity of resistance development. However, their physicochemical properties (solubility, charge, hydrophobicity/hydrophilicity), stability issues (proteolytic or enzymatic degradation, aggregation, chemical degradation), and toxicities (interactions with blood components or cellular toxicities) limit their therapeutic applications. Area covered Nanomedicine-based therapeutic delivery is an emerging concept. The AMP loaded nanoparticles have been prepared and investigated for their antimicrobial effects. In this review, we will discuss different nanomedicine-based AMP delivery systems including metallic nanoparticles, lipid nanoparticles, polymeric nanoparticles, and their hybrid systems along with their future prospects for potent antimicrobial efficacy.

Expert opinion Nanomedicine-based AMP delivery is a recent approach to the treatment of bacterial infections. The advantageous properties of nanoparticles including the enhancement of AMP stability, controlled release, and targetability make them suitable for the augmentation of AMP activity. Modifications in the nanomedicine-based approach are required to overcome the problems of nanoparticle instability, shorter residence time, and toxicity. Future rigorous studies for both the AMP loaded nanoparticle preparation and characterization, and detailed evaluations of their in vitro and in vivo antimicrobial effects and toxicities, are essential.
\end{abstract}

Keywords Antimicrobial peptide $\cdot$ Bacterial infection $\cdot$ Nanoparticles $\cdot$ Nanomedicine

\section{Introduction}

Bacterial infections substantially contribute to threats to human health globally (Fitzpatrick et al. 2019). Antibiotics have long been the drug of choice for the treatment of bacterial infections. However, with the emergence of antibiotic resistance, their effectiveness has been compromised (Ventola 2015). Several drug-resistant bacteria (including methicillin-resistant, vancomycin-resistant, penicillin-resistant, sulfonamide-resistant, and macrolide-resistant, or even multidrug-resistant) have been identified that pose a serious

Raj Kumar Thapa

r.k.thapa@ farmasi.uio.no

1 Section for Pharmaceutics and Social Pharmacy, Department of Pharmacy, University of Oslo, Blindern, P. O. Box 1068, 0316 Oslo, Norway

2 Faculty of Chemistry, Biotechnology, and Food Science, Norwegian University of Life Sciences, P.O. Box 5003, 1432 As, Norway challenge in the treatment of severe respiratory, bloodstream, urinary, topical, and surgical site infections (Tacconelli et al. 2018). Therefore, the discovery or the design of antimicrobials with lower susceptibility to antimicrobial resistance is a key for the effective treatment of bacterial infections.

Antimicrobial peptides (AMPs) are the diverse groups of bioactive peptides produced by organisms against pathogens (Magana et al. 2020). They are oligopeptides composed of up to 100 amino acids and are produced by protozoa, fungi, bacteria, plants, and animals (López-Abarrategui et al. 2012). The AMPs produced by bacteria against other similar kinds of bacteria for self-preservation and competitive advantage are termed as bacteriocins (Riley and Wertz 2002). In humans, AMPs are known to exist as evolutionary conserved products of the innate immune system (Zasloff 2002) and are produced upon exposure to potentially harmful pathogens (Bals 2000). The AMPs exhibit a cationic, amphipathic, or hydrophobic nature, and the mechanism of antimicrobial activity basically involves the electrostatic interactions with the anionic phospholipids of microbial 
cell membranes (Epand and Epand 2009) to form pores for the release of bacterial contents leading to bacterial death (Fig. 1) (Magana et al. 2020). Furthermore, AMPs can be used as signaling molecules, biomarkers, and even tumoricidal agents, as well as in tissue engineering (Magana et al. 2020). Most importantly, the propensity of resistance development by AMP can be low, which makes it a potent molecule for the treatment of bacterial infections. The details on AMPs, their mechanisms of antimicrobial activity, and immunological and receptor-mediated effects are presented elsewhere (Thapa et al. 2020).

AMPs can be potentially used for the treatment of microbial infections via topical or intravenous administration. However, they display some limitations regarding safety and bioavailability and may pose additional biological activities and functions (Dutta and Das 2016). Therefore, it is crucial to enhance the stability, safety, and bioavailability of AMPs and preferably, provide a targeted and controlled release at infected sites. Some of the stability issues are addressed using approaches like the insertion of non-natural or D-amino acids; peptide cyclization, amidation, or acetylation at the $\mathrm{N}$-terminus; and the introduction of peptide mimetics (Giuliani et al. 2007). However, even stable AMPs cannot be administered as a solution owing to several issues including their solubility (due to hydrophobic peptides), interactions with body components (e.g. with blood components when administered intravenously), susceptibility to environmental conditions other than proteases (e.g. degradation by light and oxidation), and a lack of targeting and controlled release of peptides. Therefore, the development of a suitable drug delivery system for the effective delivery of AMPs is necessary.

Nanomedicine is recognized as an approach to design nanomaterials for therapeutic and diagnostic purposes (Cavalieri et al. 2014). Nanomaterials have gained wide attention for their unique properties and effectiveness in the delivery of therapeutic agents for the treatment of a variety of ailments including cancer, ophthalmic diseases, wounds, and blood pathogens. Unique properties such as size (in nanometer range), surface properties, targetability, inherent antimicrobial properties, and ease of application allow widespread use of nanomaterials. Commercial formulations ( $>10$ marketed products) based on nanoparticles are already available for antibacterial delivery, bacterial diagnosis, and in medical devices (Zhu et al. 2014).

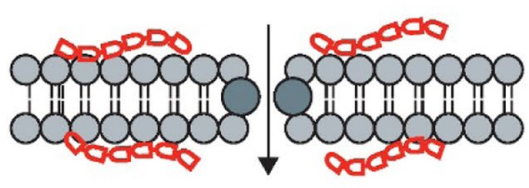

Electroporation (eg, NK-lysin)

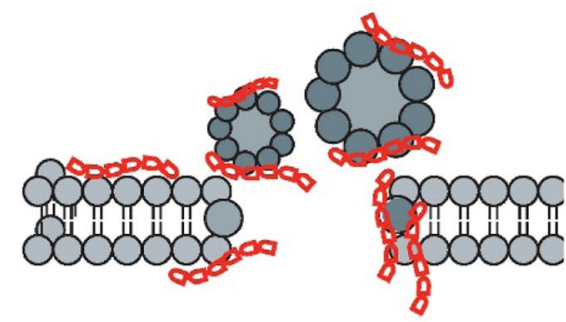

Carpet model (eg, cercopin, aurein)

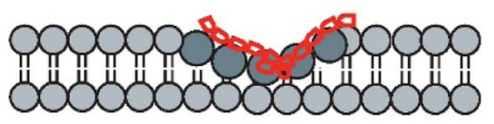

Membrane thinning or thickening (eg, PGLa, cathelicidin LL-37)

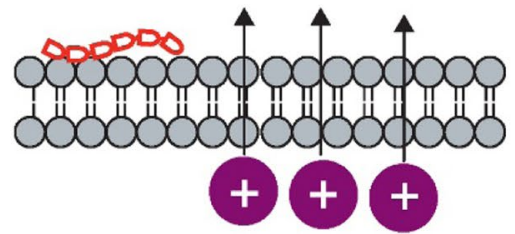

Non-lytic membrane depolarisation (eg, bovine lactoferricin, daptomycin)

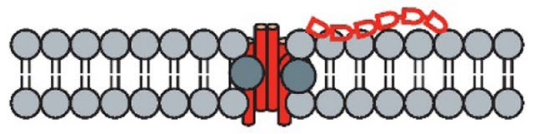

Toroidal pore (eg, magainin 2, melittin, protegrin I)

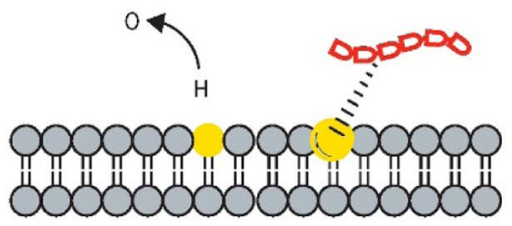

Oxidised lipid targeting (eg, temporin L, indolicidin)

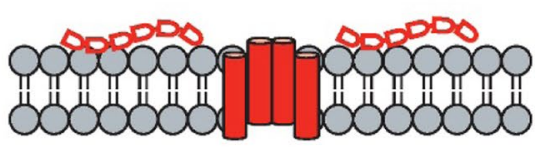

Barrel stave (eg, alamethicin)

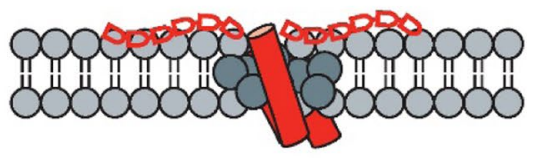

Disordered toroidal pore (eg, magainin analog, melittin)



Non-bilayer intermediate (eg, gramicidin S)

Fig. 1 Mechanisms of interactions between AMPs and bacterial membranes [reprinted with permission from (Magana et al. 2020)] 
The enhanced stability, bioavailability, and targetability of AMPs for potent antimicrobial effects can be possibly achieved by using a suitable nanocarrier system, and it is herein the recent developments in the use of nanomedicinebased AMP delivery for antibacterial effects will be discussed. In addition, future prospects in the development of a suitable nanomedicine-based AMP delivery will be addressed.

\section{Nanomedicine-based AMP delivery}

The AMPs can exhibit their antimicrobial properties via membrane permeabilizing and non-membrane permeabilizing effects as presented in Fig. 2. The potent antimicrobial effects are achieved by disrupting bacterial cell membranes, immune response modulation, and regulation of inflammation (Mookherjee and Hancock 2007). However, there is still a possibility of resistance development by gram-negative bacteria against these AMPs. The four main mechanisms of AMP resistance include: (1) proteolytic peptide degradation, (2) bacterial surface modification for target alteration, (3) production of a capsule to shield the bacterial membrane, and (4) down-regulation via immunomodulation (Band and Weiss 2015). Therefore, it is important to mitigate such mechanisms of AMP resistance to enhance their effectiveness as antimicrobial agents. The development of a suitable formulation is thus a viable alternative to at least enhance the stability (via preventing proteolytic degradation) and targetability (via membrane targeting and permeability) of AMPs. The nanomedicine-based AMP delivery approach can potentially enhance antimicrobial effectiveness and minimize the chances of resistance development.

Besides the given advantages of nanoparticles for AMP delivery, there are still some disadvantages that can affect the antimicrobial mechanisms of AMPs. The loading of larger molecules like peptides (AMPs) and proteins in nanoparticles is limited, and hence suitable methods of drug loading (e.g. by increasing the hydrophobic interactions or adjusting the electrostatic effects) should be optimized for greater efficacy (Shen et al. 2017). The AMP-loaded nanoparticles can undergo nonspecific uptake by phagocytes (Gustafson et al. 2015) resulting in degradation and clearance without induction of antimicrobial effects. This problem is most prevalent

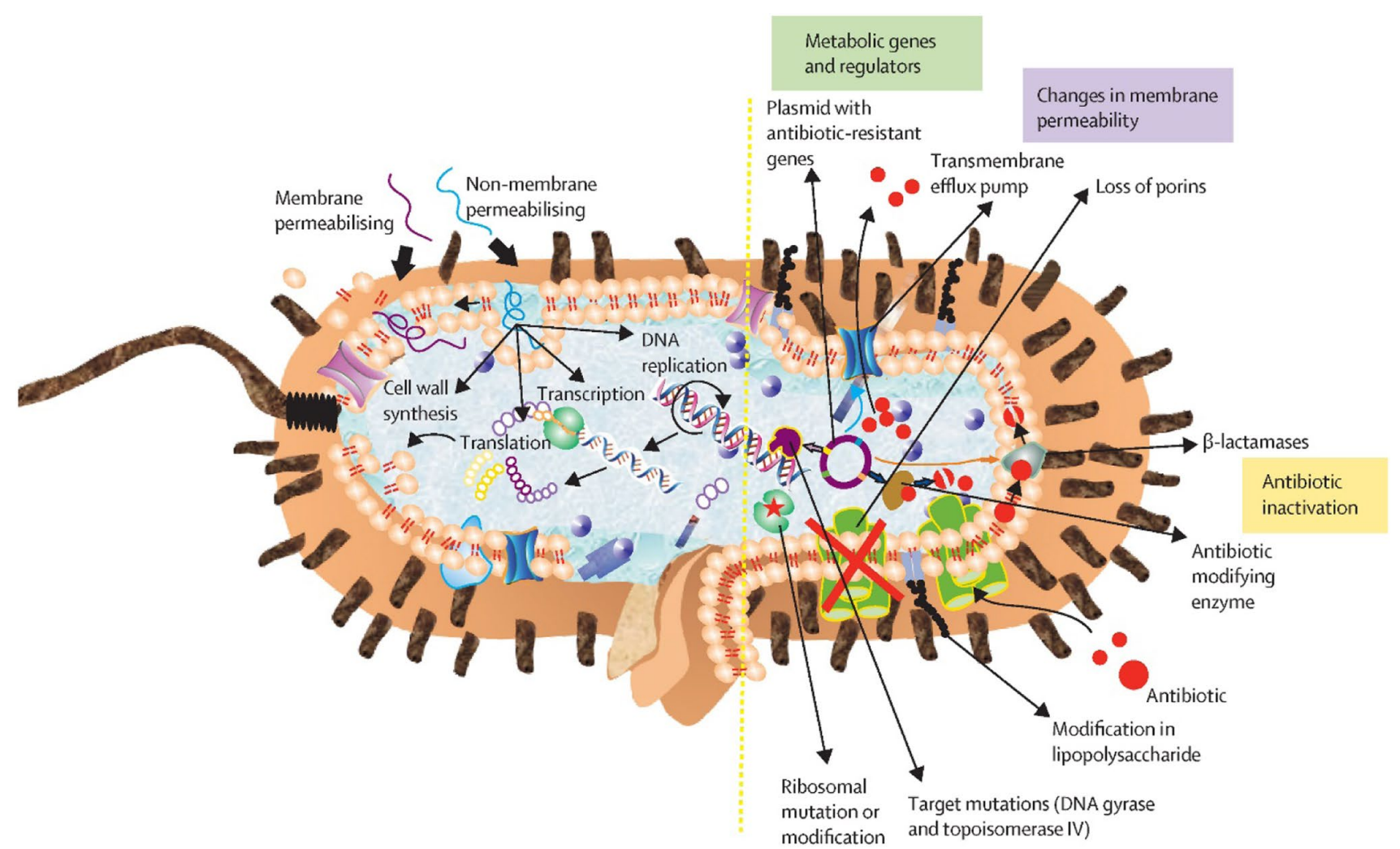

Target modifications

Fig. 2 Mechanisms of the antimicrobial effects of AMPs and factors leading to resistance development by gram-negative bacteria [reprinted with permission from (Magana et al. 2020)] 
for intravenous administration of nanoparticles and can be overcome with the stealth coating [e.g. polyethylene glycol, poly(zwitterions)] of nanoparticles (Fam et al. 2020). Different AMPs have different mechanisms of antimicrobial actions. Some of the AMPs (e.g. LL37, melittin, magainin 2) induce bacterial membrane disruption (Le et al. 2017) and hence require being released outside the bacterial membrane to induce therapeutic effects. However, in some instances, the nanoparticles can be uptaken by the microorganisms resulting in the release of AMPs intracellularly. This problem can be solved by the development of hybrid systems wherein the AMP loaded nanoparticles are incorporated within e.g. hydrogel, resulting in the stable and controlled release of AMPs in the application area to induce potent antimicrobial effects (Moorcroft et al. 2020). Other groups of AMPs (e.g. buforin II, tachyplesin, microcin J25) can act intracellularly to induce DNA damage or prevent DNA/RNA or cell wall synthesis (Le et al. 2017). The uptake of such AMP loaded nanoparticles is beneficial for intracellular peptide release and subsequent antimicrobial effects. The AMP loaded nanoparticles can release the peptides in a sustained fashion depending on the nanoparticle degradability (Meikle et al. 2017) and the influence of the microenvironment (e.g. $\mathrm{pH}$ or other external stimuli) (Yu et al. 2020), thus continuously affecting the target sites for the induction of potent antimicrobial effects.

Different nanocarriers have been investigated for their potential in AMP delivery. Nanomaterials used for the delivery of AMPs can be categorized as follows: (1) inorganic or metallic nanoparticles (e.g. gold, silver, and silica nanoparticles), (2) polymeric nanoparticles (e.g. chitosan, hyaluronic acid, and PLGA nanoparticles), (3) lipid nanoparticles (e.g. liposomes, solid lipid nanoparticles, and nanostructured lipid carriers) and (4) other nanostructures (e.g. dendrimers, carbon nanodots, and quantum dots). In addition to their nanocarrier function, some of these nanomaterials themselves can have antimicrobial effects. Schematic representation of the nanomaterials with inherent antimicrobial properties and as a nanocarrier for nanomedicine-based AMP delivery is presented in Fig. 3.

The nanomaterials with inherent antimicrobial properties vary in the mechanisms of their antimicrobial effects. The antimicrobial mechanisms of metallic nanoparticles are presented in Fig. 4. Gold nanoparticles (Au NPs) induce antimicrobial effects via heavy electrostatic attraction, accumulation at cell surfaces, and interactions with cell membranes (Chamundeeswari et al. 2010). Silver nanoparticles (Ag NPs) interfere with the cell membrane, inhibit electron transport, denature ribosomes and inhibit protein synthesis, as well as damage DNA (Yin et al. 2020). Zinc oxide nanoparticles (ZnO NPs) disrupt bacterial cell membranes and accumulate inside the cell to produce toxic hydrogen peroxide (Lallo da Silva et al. 2019). Titanium dioxide nanoparticles $\left(\mathrm{TiO}_{2} \mathrm{NPs}\right)$ damage cell membranes and release reactive oxygen species (Azizi-Lalabadi et al. 2019). Nitric oxide-releasing nanoparticles (NO NPs) release nitric oxide and produce reactive oxygen species for the induction of antimicrobial effects (Weller 2009).
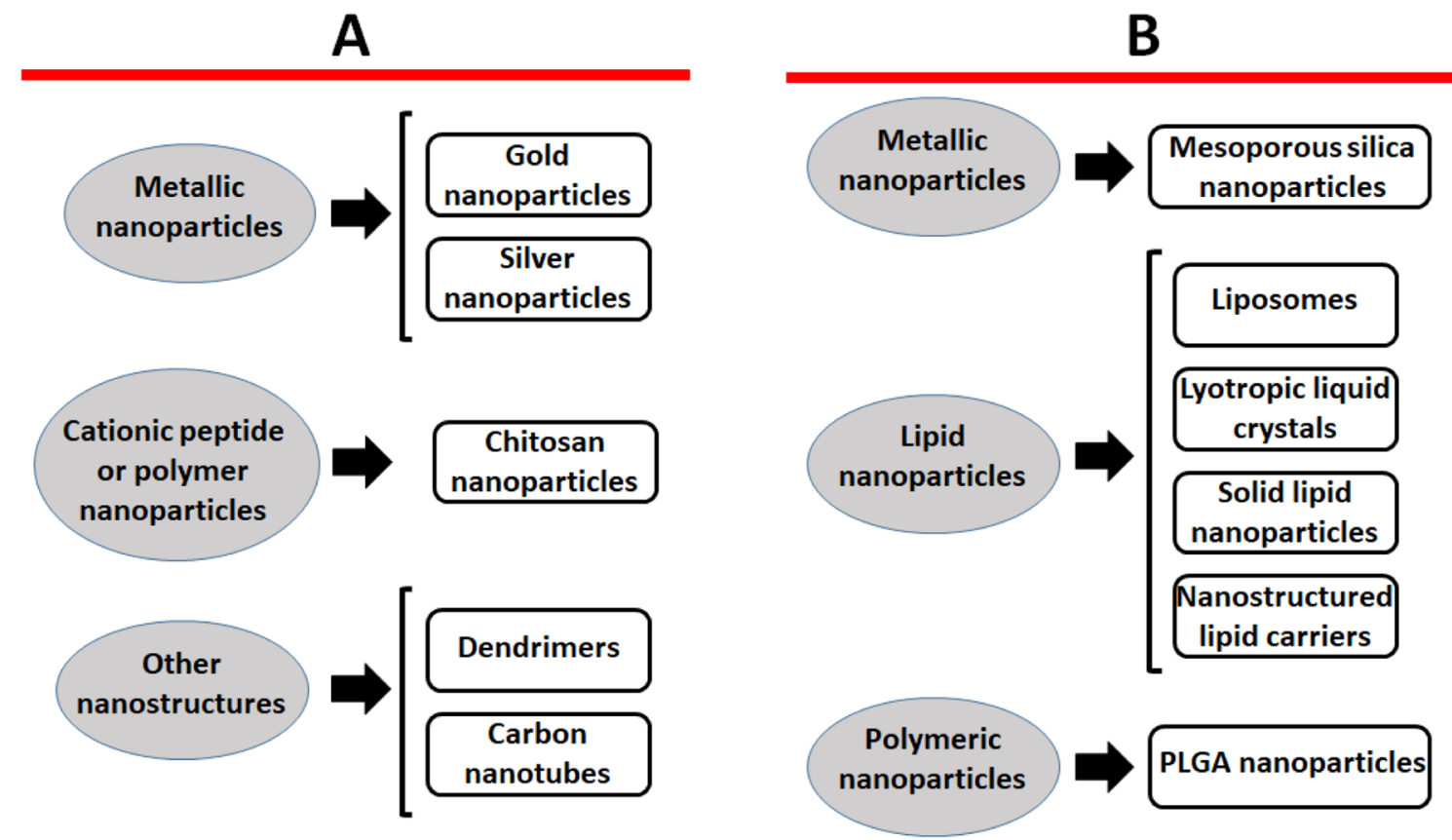

Fig. 3 Schematic representation of nanomaterials with $\mathbf{a}$ inherent antimicrobial properties and carrier functions, and $\mathbf{b}$ as only nanocarriers for AMP delivery 


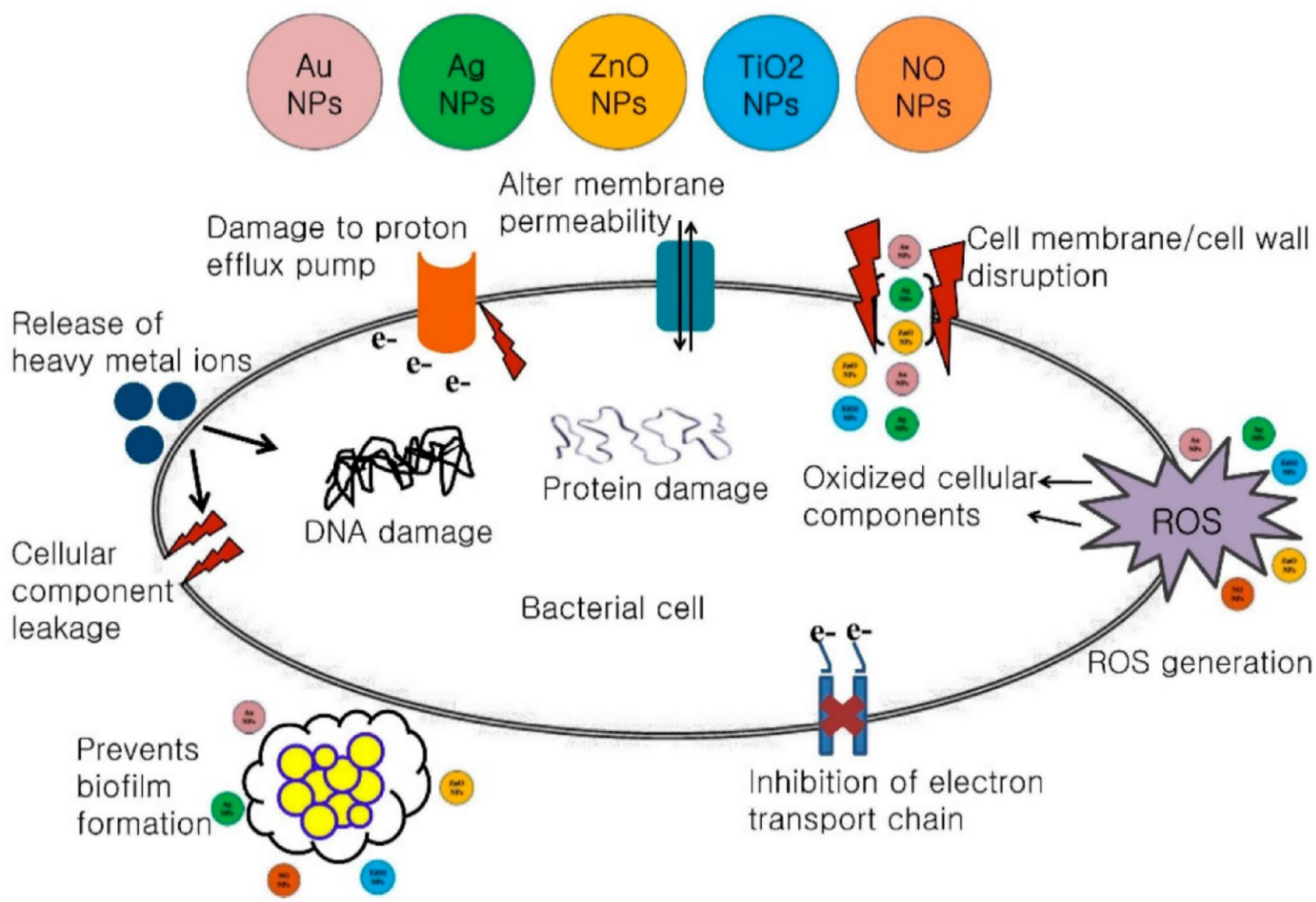

Fig. 4 Schematic representation of the mechanisms of antimicrobial effects for metallic nanoparticles [reprinted with permission from (Shaikh et al. 2019)]

In metallic nanoparticles, such as gold (Chen et al. 2015), silver (Mei et al. 2013), or mesoporous silica nanoparticles (Qi et al. 2013), the AMPs can be conjugated on the nanoparticle surface which is then available for direct interactions with bacterial cell membrane for the induction of antimicrobial effects. Furthermore, AMPs can be loaded into the mesoporous silica nanoparticles, and stimuli-responsive release can be achieved to target peptide release for antimicrobial effects (Yu et al. 2020). Furthermore, mesoporous silica nanoparticles can also enhance the membrane penetration/permeabilization of AMPs to induce antimicrobial effects (Zhao et al. 2019). Alternatively, in a combination of AMP and silver nanoparticles, the peptides can enhance the permeabilization of silver nanoparticles to access internal target sites and synergize the antimicrobial effects (Ruden et al. 2009).

Lipid nanoparticles do not possess inherent antimicrobial effects. However, they are effective carriers for AMP delivery. Liposomes are one of the widely studied lipid nanoparticles with the ability to target and control the release of AMPs for the induction of antimicrobial effects (Makhathini et al. 2019). Similarly, liquid crystalline nanoparticles, solid lipid nanoparticles, and nanostructured lipid carriers can prevent peptide degradation and promote the sustained release of AMPs (Meikle et al. 2017).

The polymeric nanoparticles composed of cationic polymers exhibit antimicrobial properties by polymer binding to the cell membrane surface via electrostatic interactions followed by insertion of the hydrophobic groups to the bacterial membranes. The formation of membrane-active conformation and subsequent membrane disruption leads to antimicrobial effects (Mortazavian et al. 2018). The schematic representation of the inherent antimicrobial mechanism of polymeric nanoparticles is presented in Fig. 5. Apart from the inherent antimicrobial properties, polymeric (e.g. chitosan, PLGA) nanoparticles can enhance the stability and control the release of AMPs to promote the antimicrobial effects (Piras et al. 2015).

Other nanostructures (e.g. dendrimers) can possess inherent antimicrobial mechanisms due to their cationic charge compositions. Dendrimers can also be formed with AMPs that allow direct peptide interactions with bacterial 
(ii) Electrostatic attraction

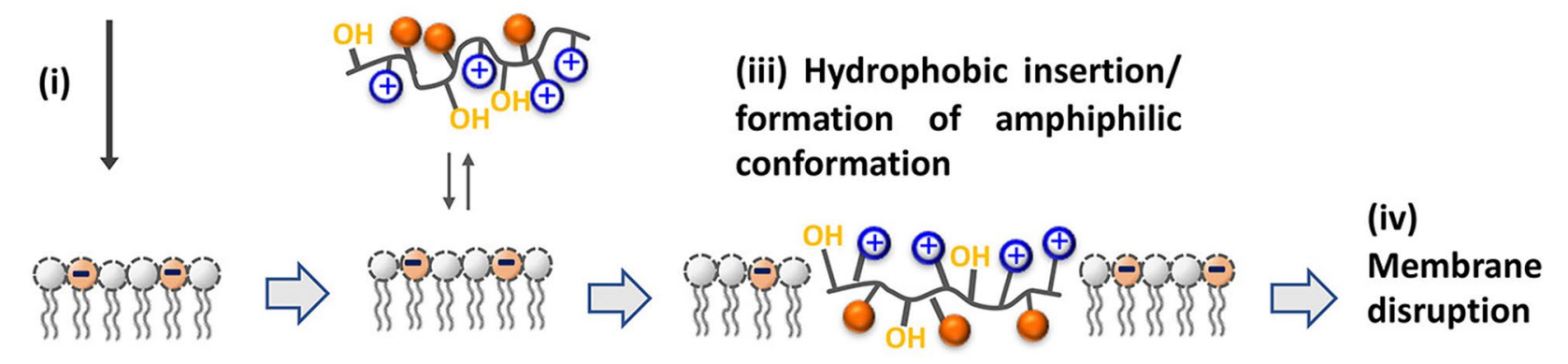

Fig. 5 Schematic representation of the antimicrobial mechanism of cationic polymers [reprinted with permission from (Mortazavian et al. 2018)]

membranes to induce antimicrobial effects (Pompilio et al. 2018). Moreover, nanostructures such as carbon nanotubes can present inherent antimicrobial effects by a physical mode or induction of oxidative stress and subsequently release the AMPs for synergizing the effects (Roccatano et al. 2017).

The combination of the antimicrobial effects of both nanomaterials and AMPs can be beneficial in inducing potent antimicrobial effects (Baptista et al. 2018). The mechanisms of antimicrobial effects target different pathways that can lead to possible synergistic effects and can potentially minimize the chances of resistance development. A schematic representation of the possible interactions between different AMP nanoparticles and bacterial membranes for the induction of antimicrobial effects is presented in Fig. 6.

\section{Recent advances in nanomedicine-based AMP delivery}

The purpose of developing a technological strategy for nanomedicine-based AMP delivery is to enhance the safety and bioavailability of AMPs and AMP stability by avoiding chemical, enzymatic, and light-induced degradations, as well as to prevent peptide aggregation and promote controlled and targeted release. The different nanomaterial systems utilized for the delivery of AMPs to treat bacterial infections are presented below.

\section{Inorganic or metallic nanoparticles for AMP delivery}

Inorganic or metallic nanoparticles have been widely studied for their potential antimicrobial activity in addition to their nanocarrier functions (Sánchez-López et al. 2020). The metallic nanoparticles are produced by different physical methods including evaporation, sputtering, photolithography, laser ablation, and electron-beam lithography
(Jamkhande et al. 2019). The chemical approach involves the reduction (using citrate, ascorbate, and sodium borohydrate) of metallic ions to form nanoparticles (Iravani et al. 2014; Slepička et al. 2019). The nanoparticle size, shape, and surface properties (zeta potential) determine their antimicrobial efficacy (Lee and Jun 2019). The large surface area and release of metal cations from the nanoparticles enhance their antimicrobial potency (Cheeseman et al. 2020). Conjugation of the nanoparticles with suitable targets can further enhance their antimicrobial effects (Lin et al. 2002). More importantly, the resistant strains of bacteria can also be treated effectively using nanoparticle conjugate systems (Rosemary et al. 2006). The major drawbacks of using metallic nanoparticles include the toxicity induced by the reagents used for nanoparticle synthesis or the precipitation and agglomeration of the nanoparticles along with their non-biodegradability. Nanoparticle aggregation can be prevented by using suitable surfactants and water soluble polymers (e.g. chitosan, polyvinyl sulphonate, or polysaccharides) for stabilization (Długosz et al. 2020). Furthermore, functionalization of the nanoparticles with AMPs can improve their antimicrobial efficacy via stabilization, prevention of agglomeration, and synergistic antibacterial effects (Chen et al. 2015). Silver and gold nanoparticles have been widely studied for their intrinsic antimicrobial effects and as a potential nanocarrier (Morales-Avila et al. 2017), whereas silica nanoparticles are evident as a suitable nanocarrier for a wide range of therapeutics including AMPs (Selvarajan et al. 2020). Inorganic or metallic nanoparticles functionalized with AMPs are elaborted below.

\section{Gold nanoparticles}

Gold nanoparticles are one of the metallic nanoparticles widely studied as a diagnostic, therapeutic, and nanocarrier system (Hu et al. 2020). The biocompatible nature of gold 


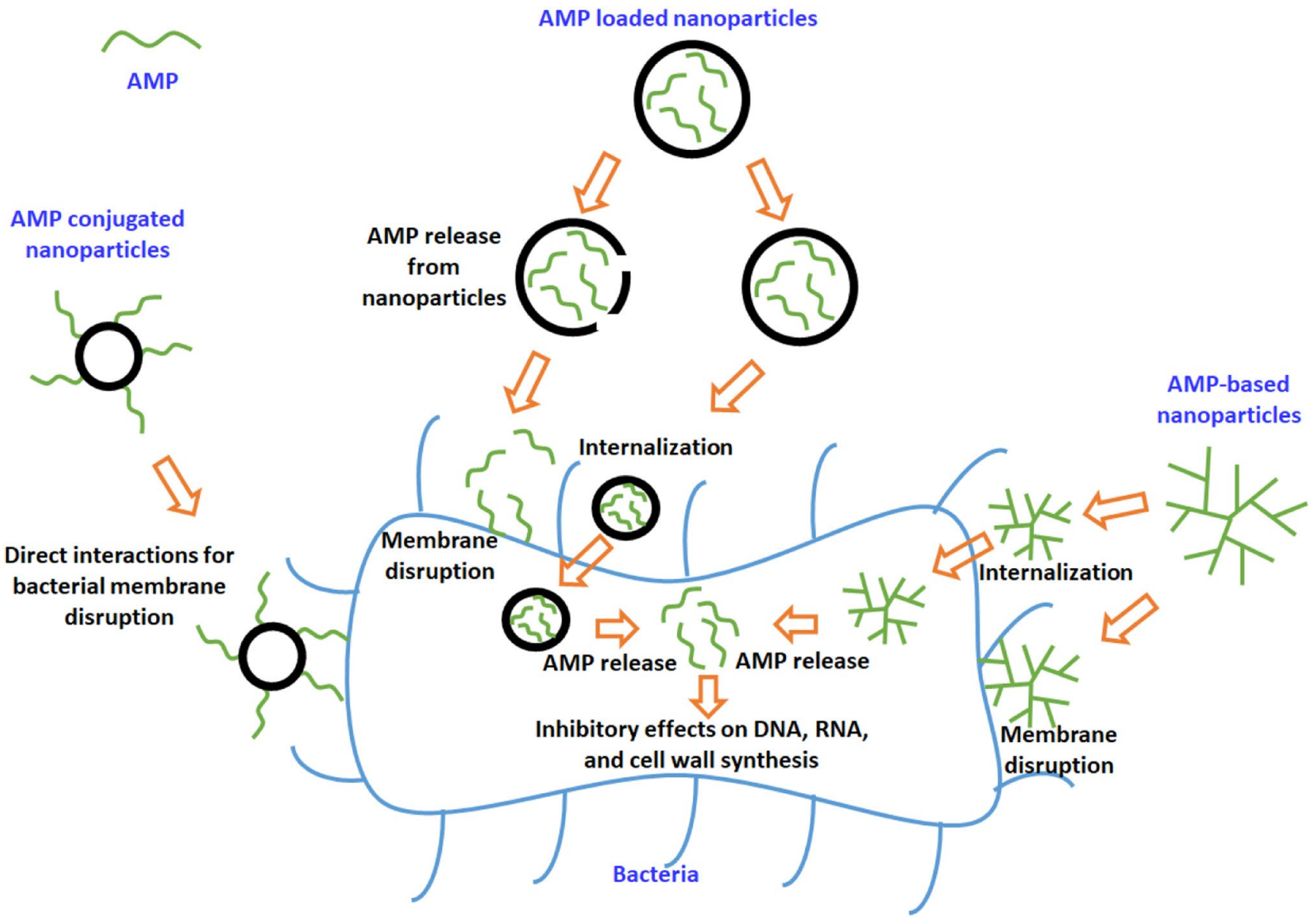

Fig. 6 Schematic representation of possible interactions between different AMP nanoparticles and bacterial membranes for the induction of antimicrobial effects

makes these nanoparticles comparatively safer than other metallic nanoparticles (Yang et al. 2015). Gold nanoparticles induce antibacterial effects by the generation of reactive oxygen species (ROS) leading to oxidative stress in the microbial cells (Mohamed et al. 2017). Recently, there is a growing interest in the use of gold nanoparticles as a carrier for AMPs. Studies involving different in vitro and in vivo models, for targeting a plethora of microorganisms, have been performed utilizing different AMP loaded gold nanoparticles (Table 1).

There are several advantages of using gold nanoparticles as a carrier for AMPs, including the enhancement of AMP stability against proteases and enzymes (Yeom et al. 2016), higher functionalization of AMPs on nanoparticle surfaces for both antibacterial and immune recognitions (Grzelczak et al. 2010), and potent antibacterial effects even against resistant bacterial strains (Casciaro et al. 2017; Wadhwani et al. 2017). The main disadvantage of the gold nanoparticles loaded with AMPs is their possible aggregation (Wadhwani et al. 2017), the longer residence time in the body following intravenous administration (Fraga et al. 2014), and shorter residence time following topical application (Arvizo et al. 2010). The AMPs can sometimes prevent the aggregation of gold nanoparticles attributed to their inherent amino acid charges. The size $(<20 \mathrm{~nm})$, shape (spherical), and surface charge (reduction in positive charge) of gold nanoparticles can be changed to enhance the elimination from the body for toxicity reduction (Rajchakit and Sarojini 2017). For the enhancement of the residence time following topical applications, suitable formulation modifications are required (e.g. combination of adhesive polymer and AMP-gold nanoparticles, or hydrogel composed of AMP-gold nanoparticles) (Moorcroft et al. 2020).

\section{Silver nanoparticles}

Silver nanoparticles (AgNPs) have been rigorously studied as a system with inherent antimicrobial effects. The potent antimicrobial activity of AgNPs is well established, and the possible mechanisms include the release of silver ions, free radical generation, cell membrane damage, and 
Table 1 Gold nanoparticle-based AMP delivery

\begin{tabular}{|c|c|c|c|c|}
\hline AMP & Treatment purpose & Target microorganisms & Outcome & References \\
\hline Vancomycin & In vitro study & $\begin{array}{l}\text { Vancomycin resistant ente- } \\
\text { rococci and } E \text {. coli }\end{array}$ & $\begin{array}{l}\approx 8-32 \text { fold reduction in } \\
\text { minimum inhibitory } \\
\text { concentration (MIC) of } \\
\text { vancomycin }\end{array}$ & (Gu et al. 2003) \\
\hline Vancomycin & In vitro study & $\begin{array}{l}\text { Vancomycin resistant } S \text {. } \\
\text { aureus, and } E \text {. coli }\end{array}$ & $\begin{array}{l}\approx 4-6 \text { fold reduction in MIC } \\
\text { of vancomycin }\end{array}$ & $\begin{array}{l}\text { (Mohammed Fayaz et al. } \\
\text { 2011) }\end{array}$ \\
\hline Surfactin & $\begin{array}{l}\text { In vivo rat wound infection } \\
\text { model }\end{array}$ & $\begin{array}{l}\text { Methicillin resistant } S . \\
\text { aureus } \text { (MRSA) }\end{array}$ & $\begin{array}{l}\text { Complete inhibition of the } \\
\text { bacteria on wounds }\end{array}$ & (Chen et al. 2015) \\
\hline $\begin{array}{l}\text { Cecropin-melittin } \\
\text { derivative (cysteine at } \\
\text { C-terminus) }\end{array}$ & $\begin{array}{l}\text { Systemic infection in a } \\
\text { mouse model }\end{array}$ & E. coli & $\begin{array}{l}\approx \text { four fold reduction in } \\
\text { MIC of cecropin-melittin } \\
\text { as compared to free } \\
\text { peptide }\end{array}$ & (Rai et al. 2016) \\
\hline PEP & In vivo rat wound model & S. aureus & $\begin{array}{l}>99 \% \text { of bacteria were } \\
\text { killed with a single dose } \\
\text { treatment }\end{array}$ & (Peng et al. 2016) \\
\hline Esculentin-1a(1-21) $\mathrm{NH}_{2}$ & In vitro study & P. aeruginosa & $\begin{array}{l}\text { Resistance against proteo- } \\
\text { lytic degradation of AMP } \\
\text { and } \approx 12 \text { fold lower mini- } \\
\text { mal bactericidal concen- } \\
\text { tration required to kill } 50 \% \\
\text { of the strain (MBC50) as } \\
\text { compared to free peptide }\end{array}$ & (Casciaro et al. 2017) \\
\hline $\mathrm{A} 3-\mathrm{APO}^{\mathrm{His}}$ & $\begin{array}{l}\text { Systemic infection in a } \\
\text { mouse model }\end{array}$ & S. Typhimurium & $\begin{array}{l}\text { Complete inhibition of bac- } \\
\text { terial colonization in mice } \\
\text { organs resulting in 100\% } \\
\text { survival of mice }\end{array}$ & (Yeom et al. 2016) \\
\hline LL37 & $\begin{array}{l}\text { Infected diabetic wound } \\
\text { mouse model }\end{array}$ & MRSA & $\begin{array}{l}>99 \% \text { reduction in wound } \\
\text { bacteria with a single dose } \\
\text { treatment }\end{array}$ & (Wang et al. 2018) \\
\hline 1018K6 & In vitro study & L. monocytogens & $\begin{array}{l}\approx 100 \% \text { killing of patho- } \\
\text { genic bacteria }\end{array}$ & (Palmieri et al. 2018) \\
\hline $\begin{array}{l}\text { Pep-H motif of human } \\
\text { neutrophil peptide-1 } \\
(\text { HNP-1) }\end{array}$ & In vitro study & $\begin{array}{l}\text { M. tuberculosis infected in } \\
\text { monocyte-derived mac- } \\
\text { rophages }\end{array}$ & $\begin{array}{l}>90 \% \text { reduction in the } \\
\text { intracellular bacteria }\end{array}$ & (Sharma et al. 2019) \\
\hline
\end{tabular}

interactions with bacterial DNA and its damage (Durán et al. 2016). Silver nanoparticles serve as a carrier of the silver ions to the bacterial membrane and cytoplasm rather than exerting direct particle-specific toxicity on bacteria (Xiu et al. 2012). This function is attributed to the minimal binding and interactions with the biological ligands (Xiu et al. 2012). Therefore, conjugation of silver nanoparticles with AMPs can be beneficial in enhancing the interactions of the peptides with bacterial membranes and then releasing silver ions for further toxicity induction in bacteria for synergistic antibacterial effects (Morales-Avila et al. 2017). Furthermore, peptide conjugation can prevent nanoparticle aggregation and enhance their stability (Pal et al. 2019). Similarly, silver nanoparticles can also enhance the stability and activity of AMPs thus promoting the antibacterial effects (Pal et al. 2016). The examples of such AMP functionalized silver nanoparticles used for the antibacterial purpose are presented in Table 2.

\section{Mesoporous silica nanoparticles (MSNs)}

Recently, MSNs have gained considerable interest in the delivery of antimicrobial agents owing to their stable frame structures, good biocompatibility, tunable surface chemistry, and high loading capacity (Jambhrunkar et al. 2014; $\mathrm{Xu}$ et al. 2015). The AMPs can be either conjugated to the surface of the MSNs or loaded into the pores for controlled release. The antimicrobial effects of AMP functionalized MSNs are dependent on the nanoparticle charge and porosity (which influence AMP loading and release) and their subsequent bacterial membrane interactions (Braun et al. 2016). The LL-37 loading was higher in anionic MSNs (via pore localization) compared to nonporous or cationic nanoparticles (via electrostatic interactions). The bacterial 


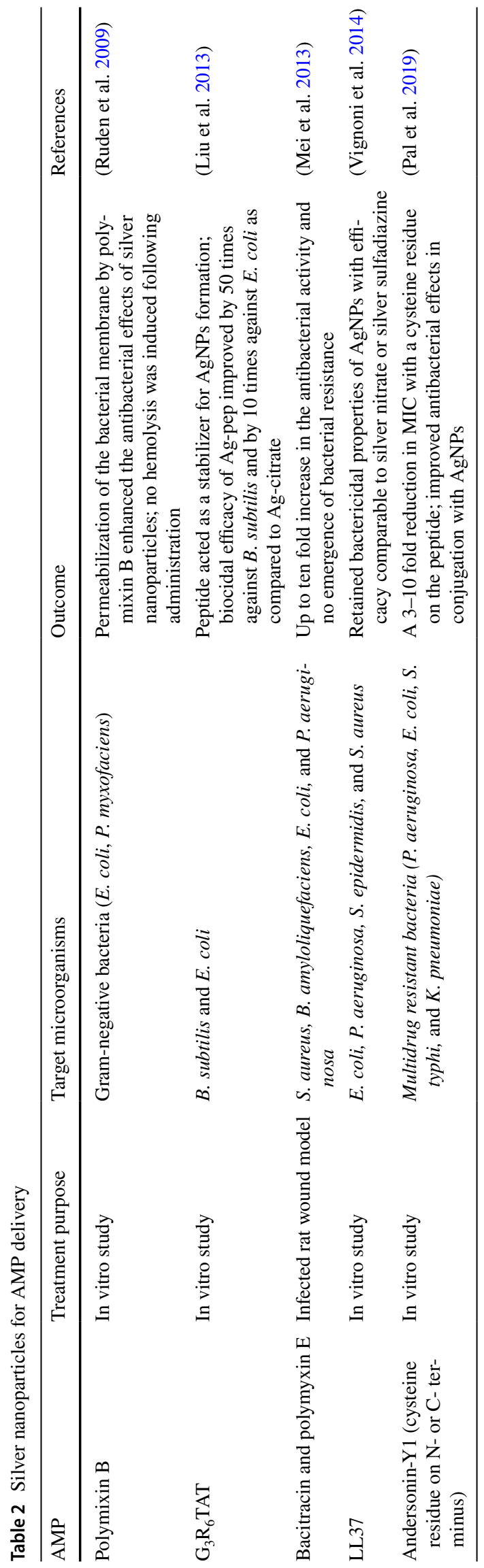

membrane disruption is attributed to peptide release from anionic MSNs and nanoparticle interactions regarding nonporous or cationic nanoparticles (Braun et al. 2016). The higher stability of the AMPs against bacterial proteases is achieved with the use of MSNs. The intravenous or oral administration of the peptide-functionalized MSNs can be utilized for the respective treatments of bacterial infections such as tuberculosis (Tenland et al. 2019) or intestinal infections (Zhao et al. 2019). Furthermore, antimicrobial effectiveness is also demonstrated in the bacterial infection of implants (Yu et al. 2020). However, for a topical application, the MSNs require an adhesive environment to prolong their residence time at the site of infection, which can be achieved through formulation modifications via incorporation into a suitable matrix (e.g. hydrogel) or an adhesive patch. The MSNs used for the delivery of different AMPs are presented in Table 3.

\section{Lipid nanoparticles for AMP delivery}

Lipid nanoparticles are one of several widely studied drug delivery systems owing to their safety, biocompatibility, and ability to transport both hydrophobic and hydrophilic molecules (García-Pinel et al. 2019). Different methods utilized in the preparation of lipid nanoparticles include thin-film hydration, reverse phase evaporation, high pressure homogenization, microemulsion, solvent emulsification evaporation, phase inversion, coacervation, super critical fluid, and ultrasonication (Akbarzadeh et al. 2013; Ganesan and Narayanasamy 2017). In addition to the widely applied intravenous administration (Anselmo and Mitragotri 2016), the lipid nanoparticles have potent applications for dermatological pathologies because of their abilities to target deeper skin layers following topical applications (de Leeuw et al. 2009). Several marketed formulations of lipid nanoparticles are available that prove their safety and efficacy as drug carriers (Puri et al. 2009). These nanoparticles have been investigated as carriers for peptide drugs for over three decades (Torchilin 2005). The AMPs can either be incorporated within the lipid nanoparticles or conjugated on the surface for antibacterial effects. Different types of lipid nanoparticles utilized for the AMP delivery include liposomes, lyotropic liquid crystals, and solid lipid nanoparticles and nanostructured lipid carriers.

\section{Liposomes}

Liposomes are the first nanomedicine approved by the regulatory agencies, which contributes to their widespread popularity and use in drug delivery (Barenholz 2012). They are spherical self-enclosed bilayers that are spontaneously formed in the aqueous suspension (Akbarzadeh et al. 2013). Phospholipids are the main components of liposomes along 
Table 3 MSNs for AMP delivery

\begin{tabular}{|c|c|c|c|c|}
\hline AMP & Treatment purpose & Target microorganisms & Outcome & References \\
\hline Vancomycin & Systemic infection in a mouse model & S. aureus & $\begin{array}{l}\text { A ten fold reduction in the bacterial } \\
\text { count as compared to the control } \\
\text { groups }\end{array}$ & (Qi et al. 2013) \\
\hline Polymyxin B & In vitro study & $\begin{array}{l}\text { P. aeruginosa, A. bau- } \\
\text { mannii, and E. coli }\end{array}$ & $\begin{array}{l}\text { Controlled release and enhanced } \\
\text { antibacterial activity compared to } \\
\text { free peptide }\end{array}$ & (Gounani et al. 2018) \\
\hline T7E21R-HD5 & $\begin{array}{l}\text { In vivo intestinal infection model in } \\
\text { mouse }\end{array}$ & Multidrug resistant E. coli & $\begin{array}{l}\text { A } 15-20 \text { fold reduction in the bacte- } \\
\text { rial count as compared to the treat- } \\
\text { ment with free peptide }\end{array}$ & (Zhao et al. 2019) \\
\hline $\mathrm{NZX}$ & In vivo tuberculosis mouse model & M. tuberculosis & $\begin{array}{l}\approx 88 \% \text { reduction in colony forming } \\
\text { units (cfu) in the lungs of mice } \\
\text { compared to untreated control }\end{array}$ & (Tenland et al. 2019) \\
\hline Melittin & $\begin{array}{l}\text { In vivo implantation model of biofilm } \\
\text { in mouse }\end{array}$ & P. aeruginosa & $\begin{array}{l}\approx 100 \% \text { bacterial killing in combina- } \\
\text { tion with an antibiotic (ofloxacin) } \\
\text { co-delivered using MSNs }\end{array}$ & (Yu et al. 2020) \\
\hline
\end{tabular}

with other lipids such as cholesterol (Monteiro et al. 2014). Their main advantages include biocompatibility, biodegradability, and minimal toxicity and immunogenicity (Madeira et al. 2010). Liposomes can incorporate both hydrophobic and hydrophilic drugs in them (Monteiro et al. 2014). They are suited for the delivery of amphiphilic peptides (e.g. AMPs) in a targeted delivery and moreover enhance stability by protecting against proteolytic degradation. However, it is of prime importance to select the suitable lipid composition for the delivery of AMPs. The lipid packing and membrane fluidity are affected by the lipid composition (the degree of phospholipid unsaturation) that consequently influences AMP encapsulation and stability (Alipour et al. 2008). The increase in fluidity reduces liposome stability, which can be improved by the addition of cholesterol; however, this can reduce the AMP encapsulation (Were et al. 2003). Furthermore, the charge on the liposome surface can further determine the encapsulation and subsequent interactions with the target sites. The coating of liposomes with other polymers enhances the stability and overall therapeutic efficacy. The benefits of using AMP loaded liposomes include their effectiveness at a lower dosage, the enhanced stability of peptides, the possibility of targeted delivery, and synergistic effects with potential combinations of other antimicrobial agents to prevent resistance development. The examples of the liposomal formulations for AMP delivery are presented in Table 4.

\section{Lyotropic liquid crystals}

Lipids such as glyceryl monooleate have the ability to form liquid crystals that can organize themselves as lamellar, cubic, and hexagonal phases (Fig. 7). Factors affecting the adoption of a particular liquid crystalline phase include lipid composition, temperature, water content, and additives
(Huang and Gui 2018). Macroscopically, liquid crystals behave as fluids, but they possess an intricate crystal-like nanostructure that can control the diffusion of the entrapped molecules thus allowing a sustained delivery (Dierking and Al-Zangana 2017). High viscosity, however, makes them unsuitable for parenteral administration (Madheswaran et al. 2019). Dispersing the liquid crystals with the aid of a stabilizer (e.g. poloxamer 407) can overcome this problem by the formation of liquid crystal nanoparticles (i.e. cubic phases termed as cubosomes and hexagonal phases termed as hexosomes) (Amar-Yuli et al. 2007; Madheswaran et al. 2019). These nanoparticles can incorporate both the hydrophilic and hydrophobic molecules, respectively, in their water channels and lipid cores (Thapa et al. 2015). The exploration of the potential of liquid crystalline nanoparticles as a carrier for AMPs has recently begun (Boge et al. 2016). The examples of lyotropic liquid crystals studied for their potential as AMP carriers are presented in Table 5.

\section{Solid lipid nanoparticles (SLNs) and nanostructured lipid carriers (NLCs)}

SLNs and NLCs are recently developed nanocarrier systems that serve as alternatives to liposomes. This is attributed to their improved stability, encapsulation efficacy, shelf life, and feasibility in large-scale manufacturing (Ghasemiyeh and Mohammadi-Samani 2018). These nanocarriers are composed of lipids that melt at temperatures above $40{ }^{\circ} \mathrm{C}$. SLNs are composed of a matrix of solid lipid particles, whereas NLCs are composed of solid lipid immersed in oil droplets, both enclosed with suitable surfactants (Mukherjee et al. 2009; Beloqui et al. 2016). Both SLN and NLC are non-toxic and biodegradable (Doktorovova et al. 2014; Doktorovová et al. 2016), which can encapsulate a range of chemically different bioactive (including peptides (AMPs) 


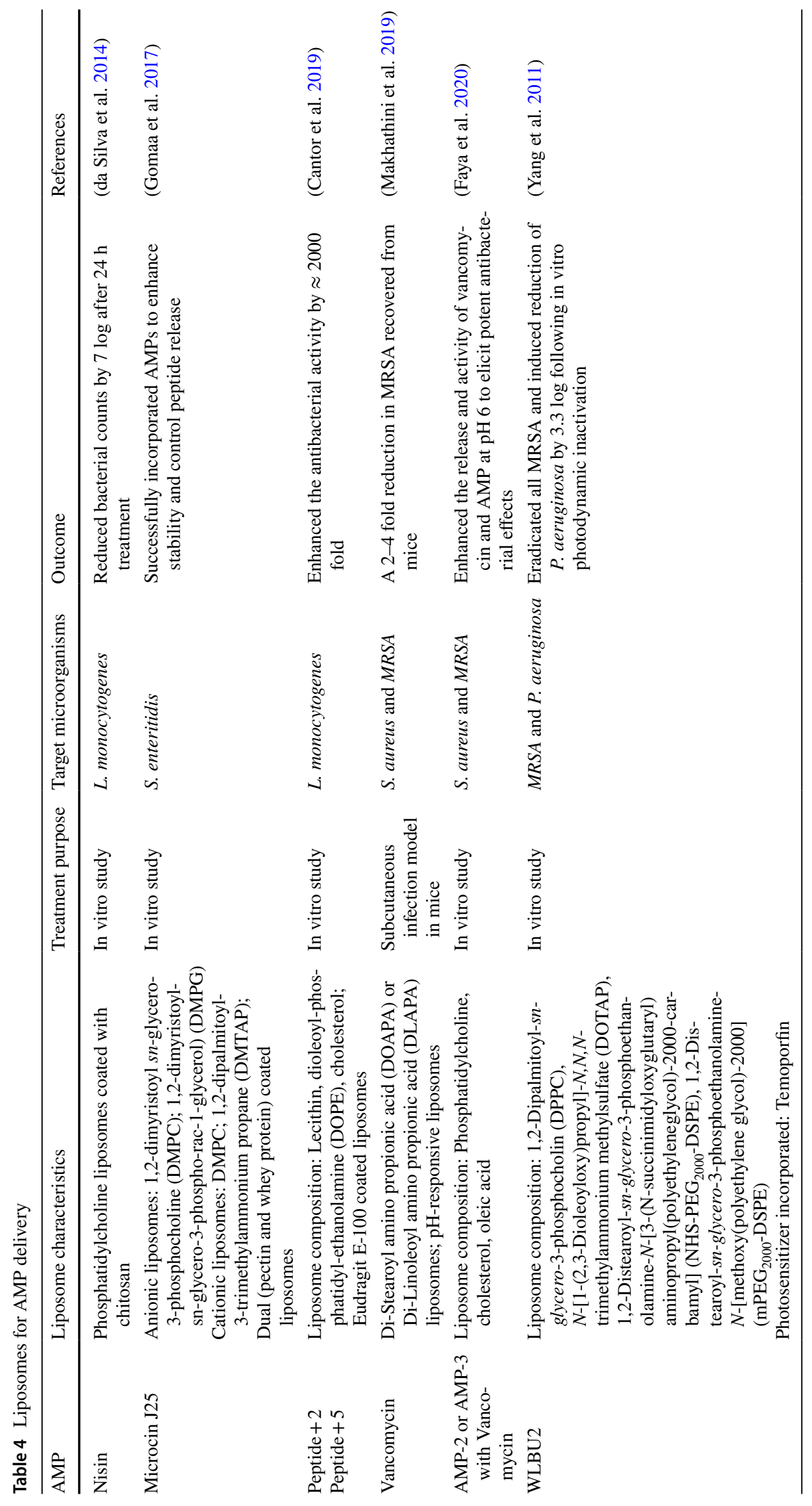




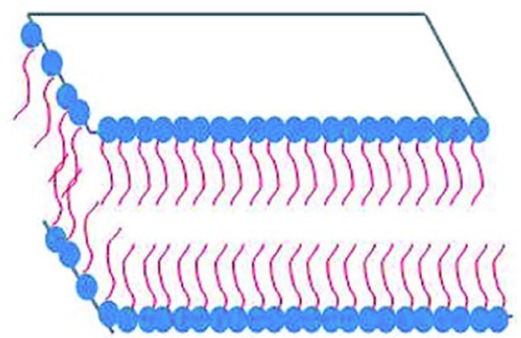

(a)

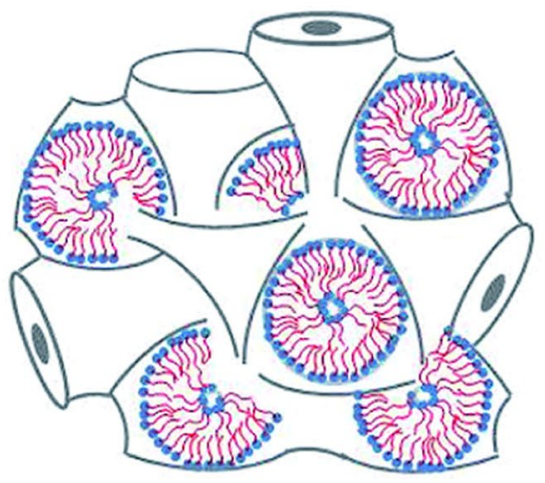

(d)

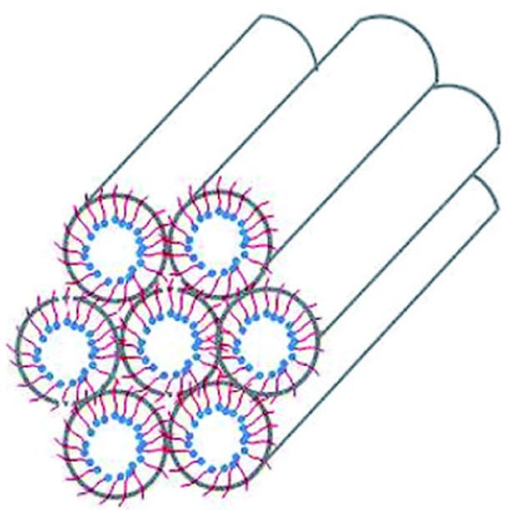

(b)

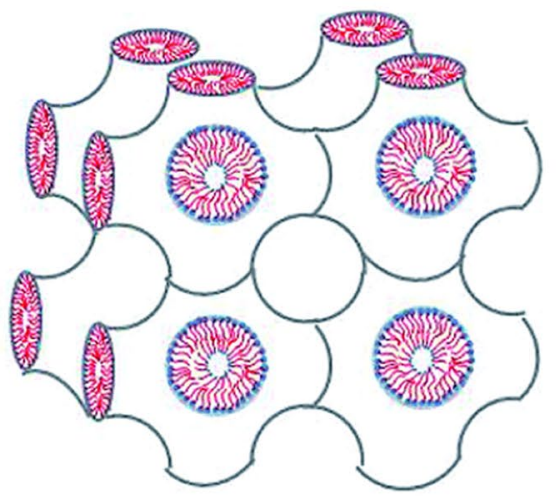

(e)

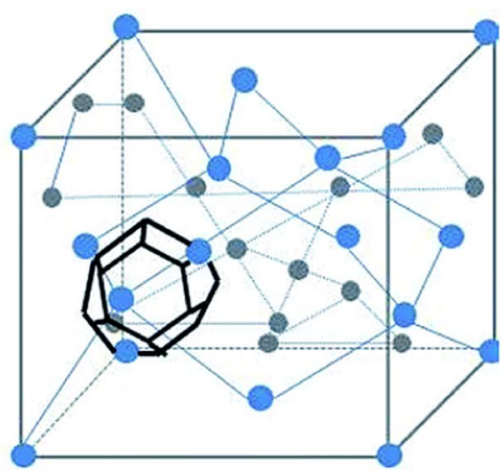

(c)

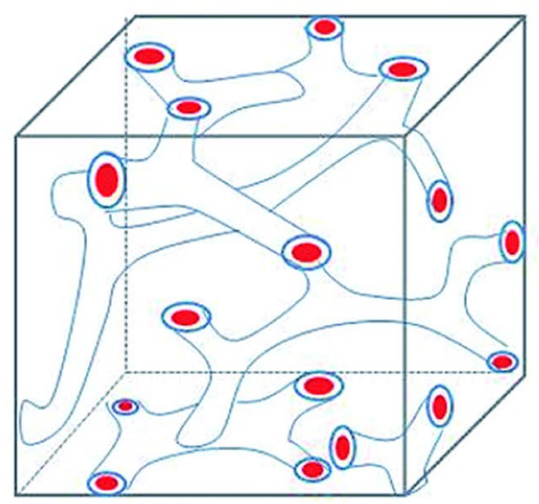

(f)
Fig. 7 Schematic representation of the lyotropic liquid crystalline phases commonly found in neutral lipid/water systems: a Lamellar phase, $\mathbf{b}$ reverse hexagonal phase, $\mathbf{c}$ reversed micellar cubic of $\mathrm{Fd} 3 \mathrm{~m}$,

and proteins) (Almeida and Souto 2007; Souto et al. 2007) with the possibility for surface modification. They can modify the release profile of the AMPs, which is attributed to their solid core (Fumakia and Ho 2016; Garcia-Orue et al. 2016). A disadvantage of SLNs over NLCs is their lower AMP loading capacity and non-uniform diffusion (Yingchoncharoen et al. 2016). Both SLNs and NLCs are suitable for oral, ocular, and parenteral administration but have been most successful in dermal administration of bioactive (Doktorovová et al. 2016) leading to the development of several marketed formulations for cosmetic use (Battaglia and Ugazio 2019). The lipophilic nature of lipid ingredients used in SLNs and NLCs limits their entrapment of polar peptides. Hence, methods such as the double emulsion technique (Becker Peres et al. 2016) and hot and cold pressure homogenization (Kasongo et al. 2012) can be used, respectively, for SLNs and NLCs to improve their loading efficacy. The peptides and proteins with poor aqueous solubility can be formulated into NLCs, which are optimal for d reversed bicontinuous cubic $(1 \mathrm{~m} 3 \mathrm{~m})$, e reversed bicontinuous cubic $(\mathrm{Pn} 3 \mathrm{~m})$, and $\mathbf{f}$ reversed bicontinuous cubic (la3d) [reprinted with permission from (Huang and Gui 2018)]

dermal applications because of their abilities to enhance skin penetration and retention, something attributable to their occlusive effects (intact film is formed by NLCs on the surface) (Lewies et al. 2017). The examples of SLNs and NLCs explored for their ability to deliver AMPs are presented in Table 6.

\section{Polymeric nanoparticles for AMP delivery}

Polymeric nanoparticles (composed of synthetic or natural polymers) have been extensively studied for the improvement of therapeutic efficacy and reduction of toxicity for pharmaceutical actives, which is attributed to their biocompatible and biodegradable nature (Bharathala and Sharma 2019). Biodegradable polymeric nanoparticles offer the potential for a sustained release profile of drugs with unique pharmacokinetics for effective drug delivery (Begines et al. 2020). Non-biodegradable polymers release the drugs via diffusion control and prevent a burst release evident for 
Table 5 Lyotropic liquid crystals for AMP delivery

\begin{tabular}{|c|c|c|c|c|}
\hline AMP & Treatment purpose & Target microorganisms & Outcome & References \\
\hline KSL-W & In vitro study & Multispecies oral biofilm & $\begin{array}{l}\text { Peptide loaded liquid crystals induced } \\
100 \% \text { inhibition of biofilm growth }\end{array}$ & (Bernegossi et al. 2015) \\
\hline $\begin{array}{l}\text { AP114 } \\
\text { DPK-060 } \\
\text { LL-37 }\end{array}$ & In vitro study & $\begin{array}{l}\text { S. aureus, MRSA, P. aeruginosa, E. coli, } \\
\text { and A. baumannii }\end{array}$ & $\begin{array}{l}\text { Cubosomes loaded with peptides } \\
\text { AP114 and DPK-060 retained the } \\
\text { antimicrobial activity of the peptides } \\
\text { whereas those loaded with LL- } 37 \\
\text { had a reduction in the bactericidal } \\
\text { properties; the antimicrobial activity } \\
\text { was reduced for all AMP-loaded } \\
\text { hexosomes }\end{array}$ & (Boge et al. 2016) \\
\hline $\begin{array}{l}\text { Gramicidin } \\
\text { A, melit- } \\
\text { tin, alame- } \\
\text { thicin }\end{array}$ & In vitro study & $\begin{array}{l}\text { No antimicrobial studies were per- } \\
\text { formed }\end{array}$ & $\begin{array}{l}\text { The AMP encapsulation in cubosomes } \\
\text { prevented peptide degradation and } \\
\text { promoted the sustained release }\end{array}$ & (Meikle et al. 2017) \\
\hline $\begin{array}{l}\beta \text {-defensin-3 } \\
\text { peptide } \\
\text { fragment } \\
\text { (D1-23) }\end{array}$ & In vitro study & S. mutans & $\begin{array}{l}\text { The D1-23 loaded cubosomes induced } \\
\approx \text { ten fold reduction in the bacterial } \\
\text { biomass following } 24 \mathrm{~h} \text { treatment as } \\
\text { compared to D1-23 only }\end{array}$ & (Aida et al. 2018) \\
\hline AP114 & In vitro study & S. aureus and MRSA & $\begin{array}{l}\text { The AP114 loaded in freeze-dried and } \\
\text { re-hydrated liquid crystal nanoparticle } \\
\text { stabilized with trehalose enhanced the } \\
\text { antibacterial activity by } 2-4 \text { fold }\end{array}$ & (Boge et al. 2018) \\
\hline DPK-060 & $\begin{array}{l}\text { Ex vivo pig skin } \\
\text { wound infection } \\
\text { model }\end{array}$ & S. aureus & $\begin{array}{l}\text { The antimicrobial effects of the peptides } \\
\text { loaded in cubosomes were retained } \\
\text { without any observed additional } \\
\text { benefits }\end{array}$ & (Håkansson et al. 2019) \\
\hline LL-37 & In vitro study & $\begin{array}{l}\text { No antimicrobial studies were per- } \\
\text { formed }\end{array}$ & $\begin{array}{l}\text { pH-adjustable peptide nanocarriers } \\
\text { were successfully developed for } \\
\text { potential applications in pathology- } \\
\text { specific pH-guided delivery of AMPs }\end{array}$ & (Gontsarik et al. 2021) \\
\hline
\end{tabular}

Table 6 SLNs and NLCs for AMP delivery

\begin{tabular}{|c|c|c|c|c|}
\hline AMP & Treatment purpose & Target microorganisms & Outcome & References \\
\hline LL-37 & In vitro study & S. aureus and E. coli & $\begin{array}{l}\text { LL-37 loaded SLNs improved the antibacte- } \\
\text { rial effects by } 1.5-2 \text { fold with the ability to } \\
\text { modify the release from the nanocarriers }\end{array}$ & (Fumakia and Ho 2016) \\
\hline LL-37 & In vitro study & E. coli & $\begin{array}{l}\text { LL- } 37 \text { loaded NLCs retained the peptide } \\
\text { bioactivity and the antibacterial efficacy } \\
\text { against } E \text {. coli }\end{array}$ & (Garcia-Orue et al. 2016) \\
\hline Nisin Z & In vitro study & S. aureus, S. epidermidis, and E. coli & $\begin{array}{l}\text { Nisin } \mathrm{Z} \text { presented additive interactions with } \\
\text { antibiotics, in particular with novobiocin; } \\
\text { nisin Z-loaded NLCs exhibited antibacte- } \\
\text { rial effects against Gram-positive bacteria } \\
\text { at physiological } \mathrm{pH} \text { with enhanced efficacy } \\
(\approx \text { eight fold higher) in combination with } \\
\text { EDTA }\end{array}$ & (Lewies et al. 2017) \\
\hline Polymyxin & In vitro study & P. aeruginosa (resistant strains) & $\begin{array}{l}\text { The encapsulation efficiency of Polymyxin } \\
\text { in SLNs was }>90 \% \text {, and these SLNs were } \\
\text { effective against the resistant strains of } P \text {. } \\
\text { aeruginosa }\end{array}$ & (Severino et al. 2017) \\
\hline
\end{tabular}

biodegradable polymers (Bharathala and Sharma 2019). The pharmaceutical actives can be adsorbed, encapsulated, dissolved, or covalently bound to the polymeric nanoparticles (as nanospheres, nanocapsules, or prodrugs) based on their compositions (Sobczak et al. 2013). Different methods used for the preparation of polymeric nanoparticles include emulsification or interfacial polymerization, solvent displacement and interfacial deposition, emulsification/solvent 
evaporation, desolvation, and salting out (Pinto Reis et al. 2006). As a nanocarrier for AMPs, the release rate from polymeric nanoparticles is dependent on the following: (a) polymer characteristics (hydrophobic-hydrophilic properties, molecular weight, architecture, degree of crystallinity, surface charge, and polydispersity); (b) process conditions (temperature, ionic strength, $\mathrm{pH}$ ); and (c) peptide properties (surface charge, hydrophobicity/hydrophilicity) (Piotrowska and Sobczak 2014). The different concurrent complex mechanisms that control the release of AMPs from polymeric nanocarriers include: (a) diffusion through the nanocarriers, (b) matrix erosion, or (c) osmotic pressure (Fredenberg et al. 2011).

Prodrugs (inactive precursors) of the AMPs can be prepared by their covalent attachment to the synthetic polymers via a physiologically labile bond (e.g. amide, ester, carbonate, anhydride) (Ringsdorf 1975). Different techniques utilized for the preparation of prodrugs include coupling, inverse conjugation, polymerization, and macromonomer methods (Khandare and Minko 2006; Ulbrich et al. 2016). The release of a peptide is possible via chemical or enzymatic biotransformation such that AMP is both bioactive and bioavailable in these systems. The factors affecting AMP release from the macromolecular conjugates include the polymer properties (hydrophilicity, molecular weight, polydispersity, and morphology), the lability of covalent bond, the length of the spacer, the peptide load, and the particle size of the carrier (Gebelein 1985). Polymeric carriers can enhance the antimicrobial effects of peptides (Haynie et al. 1995). For example, macromolecular conjugates of phosphoesters (HHC10 peptide with an extended sequence of N-terminal cysteine) displayed higher antibacterial effects against both gram-negative (E. coli, $P$. aeruginosa) and gram-positive bacteria ( $S$. aureus) as compared to free peptides attributable to the structural similarity among the carriers to the components of the bacterial cell wall (e.g., teichoic and nucleic acids) (Pranantyo et al. 2016). Additionally, conjugates displayed reduced toxicity and lower hemolytic activity compared to free peptides. Controlled placement of peptide functional groups is possible with the use of polymeric conjugates. The self-assembly of poly(acrylic acid)b-polystyrene-tritrpticin conjugates into micellar aggregates led to the position of tritrpticin segment on the micellar surface and enhanced the antimicrobial effects as compared to free peptides (Becker et al. 2005). The stability of peptides can also be enhanced by the bioconjugation of AMPs to biodegradable polyester and poly(ester-carbonate) matrices (Sobczak et al. 2014).

Different polymers used for the polymeric nanosystems include chitosan, polyethylene glycol (PEG), polylacticco-glycolic acid (PLGA), alginates, poly(acrylic acid)b-polystyrene, pectin, etc. The examples of polymeric nanoparticles utilized for the delivery of AMPs are presented in Table 7.

\section{Other nanostructures for AMP delivery}

Besides lipid, metallic, and polymeric nanoparticles, the nanostructures with potential for AMP delivery are dendrimers and carbon nanotubes. Dendrimers are hyperbranched polymeric three-dimensional structures with inherent antimicrobial properties (McCarthy et al. 2005). The advantages of dendrimers include the ease of synthesis and low manufacturing costs (Gide et al. 2018). The inherent antimicrobial effects of dendrimers are a result of increased bacterial cell membrane permeability and subsequent lysis caused by electrostatic interactions with the negatively charged bacterial membranes (García-Gallego et al. 2017; Scorciapino et al. 2017). Pompilio et al. identified the in vitro antibacterial activity of dG3KL and dTNS 18 peptide dendrimers comparable to tobramycin against both planktonic and biofilm $P$. aeruginosa at a non-toxic in vivo dose (Pompilio et al. 2018). Gide et al. developed lipidated amphiphilic dendrimers with potent antimicrobial activity against gram-negative and grampositive bacteria including multi-drug resistant strains (Gide et al. 2018). The AMPs can be either conjugated to the dendrimer structure or can themselves form dendrimeric structures useful for the treatment of bacterial infections.

Carbon nanotubes possess outstanding physical properties and tuneable morphologies (Yick et al. 2015), and they can be functionalized for therapeutic delivery. Dependent on the number of concentric layers, carbon nanotubes are classified as single-walled carbon nanotubes (0.4-2 $\mathrm{mm}$ diameter) and multi-walled carbon nanotubes (10-100 $\mathrm{nm}$ diameter). They exhibit inherent antibacterial activity via physical mode and the induction of oxidative stress resulting in bacterial cell membrane damage (Akhavan et al. 2011; Bai et al. 2011). Furthermore, the silver-coated carbon nanotubes have demonstrated remarkable antibacterial activity due to the combined mechanisms of silver nanoparticles and carbon nanotubes (Brahmachari et al. 2014; Chaudhari et al. 2015). However, their main drawbacks are non-biodegradability, toxicity to the eukaryotic cells, and aggregation in physiological fluids (Brahmachari et al. 2011; Vardharajula et al. 2012). The adsorption or conjugation of AMPs to silvercoated carbon nanotubes could prevent aggregation and enhance the antibacterial activity attributed to the combined effects of each component. The AMPs can be adsorbed or conjugated onto the carbon nanotubes to elicit synergistic antibacterial activity following application to the infection site (Roccatano et al. 2017). This combination system can prevent carbon nanotube aggregation as well as enhance the AMP stability. Chaudhari et al. developed AMP $\left(\mathrm{TP}_{359}\right)$ 
Table 7 Polymeric nanoparticles for AMP delivery

\begin{tabular}{|c|c|c|c|c|c|}
\hline Polymer & AMP & Treatment purpose & Target microorganisms & Outcome & References \\
\hline Chitosan & Vancomycin & In vitro study & S. aureus & $\begin{array}{l}\text { Decreased bacterial count } \\
\text { by } 3 \text { orders of magnitude } \\
\text { after } 24 \mathrm{~h} \text { and complete } \\
\text { inhibition after } 48 \mathrm{~h} \text { of } \\
\text { nanoparticle treatment, } \\
\text { similar to free Vancomy- } \\
\text { cin treatment }\end{array}$ & (Cerchiara et al. 2015) \\
\hline Chitosan & Temporin B & In vitro study & S. epidermidis & $\begin{array}{l}\text { A sustained antibacterial } \\
\text { action for at least } 4 \text { days, } \\
\text { with up to } 4 \text { log reduc- } \\
\text { tion in viable bacteria } \\
\text { as compared to plain } \\
\text { chitosan nanoparticles }\end{array}$ & (Piras et al. 2015) \\
\hline Chitosan & Ultrashort AMP (RBRBR) & In vitro study & S. aureus & $\begin{array}{l}\text { A } 3 \text { log reduction in bacte- } \\
\text { rial colonies as compared } \\
\text { to bare nanoparticles and } \\
\text { a } 5 \text { log reduction as com- } \\
\text { pared to control bacteria }\end{array}$ & (Almaaytah et al. 2017) \\
\hline Chitosan & Pep-H & In vitro study & M. tuberculosis & $\begin{array}{l}\text { Significant reduction in cfu } \\
(>90 \%) \text { achieved by pep- } \\
\text { tide loaded nanoparticles } \\
\text { at } 5-10 \text { times lower con- } \\
\text { centration as compared to } \\
\text { free peptide }\end{array}$ & (Sharma et al. 2019) \\
\hline PLGA & GIBIM-P5S9K & In vitro study & $\begin{array}{l}\text { E. coli, } M R S A \text {, and } P \text {. } \\
\text { aeruginosa }\end{array}$ & $\begin{array}{l}\text { Inhibited bacterial growth } \\
\text { at } 20 \text { fold lower concen- } \\
\text { tration as compared to } \\
\text { free peptide }\end{array}$ & (Cruz et al. 2017) \\
\hline PLGA & $\begin{array}{l}\text { GIBIM-P5S9K (G17) and } \\
\text { GAM019 (G19) }\end{array}$ & In vitro study & MRSA, E. coli & $\begin{array}{l}\text { Improved antibacterial } \\
\text { activity by decreasing } \\
\text { MIC50 from } 1.5 \text { to } 0.2 \\
\text { (G17 nanoparticles) and } \\
0.7 \text { (G19 nanoparticles) } \\
\mu \mathrm{M} \text { against } M R S A \text {, and } \\
\text { from } 12.5 \text { to } 3.13 \mu \mathrm{M} \text { for } \\
\text { E. coli }\end{array}$ & $\begin{array}{l}\text { (Gómez-Sequeda et al. } \\
\text { 2020) }\end{array}$ \\
\hline
\end{tabular}

bio-conjugated silver-coated single-walled carbon nanotubes that exhibited improved antibacterial effects (MIC was reduced by $8-16$ fold as compared to silver-coated singlewalled carbon nanotubes) against gram-positive ( $S$. aureus and S. pyogenes) and gram-negative (S. enterica and E. coli) bacteria, with non-toxicity to eukaryotic cells (Chaudhari et al. 2016). Similar approaches can be used to develop AMP functionalized carbon nanotubes for the induction of potent antibacterial effects.

\section{Nanomedicine-based hybrid systems for AMP delivery}

Besides nanoparticles, different hybrid systems based on nanomedicine have been studied for AMP delivery. Stimuli/microenvironment-responsive (Moorcroft et al. 2020) or assembly-based systems (Pazos et al. 2016) have been developed for the enhancement of peptide stability and therapeutic efficacy in addition to controlled release properties. Moorcroft et al. developed a nanoparticle-loaded hydrogel for the light-activated release and photothermal enhancement of AMPs as presented in Fig. 8 (Moorcroft et al. 2020). Herein the AMPs (IK8, IRIKIRIK-CONH were loaded into the liposomes that were then incorporated within the poly(ethylene glycol) (PEG) hydrogel along with gold nanorods. This hybrid system enhanced the stability of peptides by preventing proteolysis and provided a triggered release of AMPs. The laser irradiation of $860 \mathrm{~nm}$ at $2.1 \mathrm{~W} \mathrm{~cm}^{-2}$ led to photothermal effects of gold nanorods, increasing the temperature up to $55^{\circ} \mathrm{C}$ and triggering the release of peptides from liposomes, resulting in antibacterial activities against $P$. aeruginosa and $S$. aureus. Importantly, laser irradiation of $860 \mathrm{~nm}$ at $2.4 \mathrm{~W} \mathrm{~cm}^{-2}$ increased the temperature up to $60{ }^{\circ} \mathrm{C}$, which could treat two rounds of fresh $S$. aureus, demonstrating their therapeutic efficacy for 


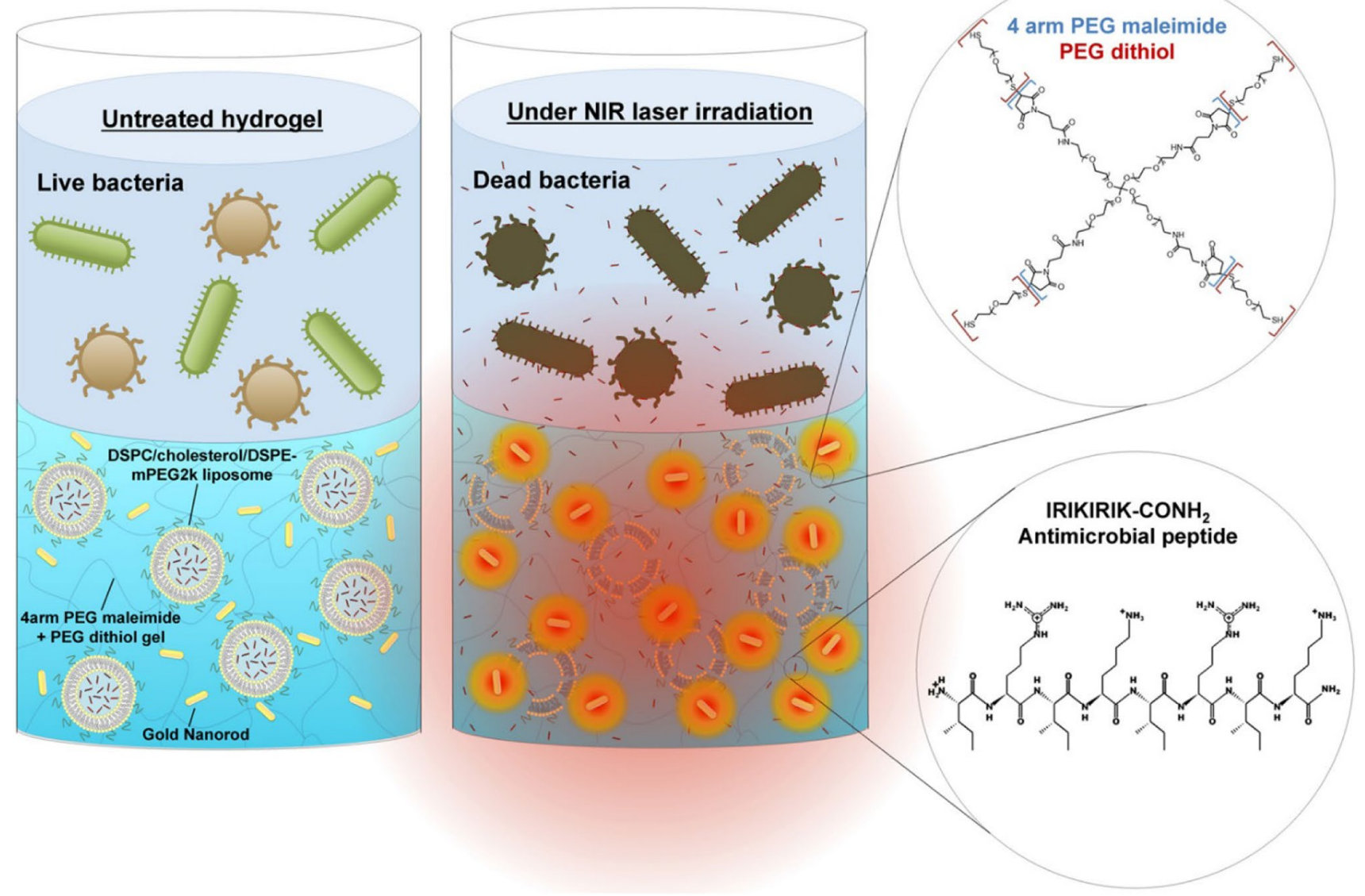

Fig. 8 Schematic representation of the PEG-based hydrogel containing gold nanorods and antimicrobial peptide (IK8)-loaded liposomes, demonstrating the mechanism for the NIR light-triggered release of AMPs [reprinted with permission from (Moorcroft et al. 2020)]
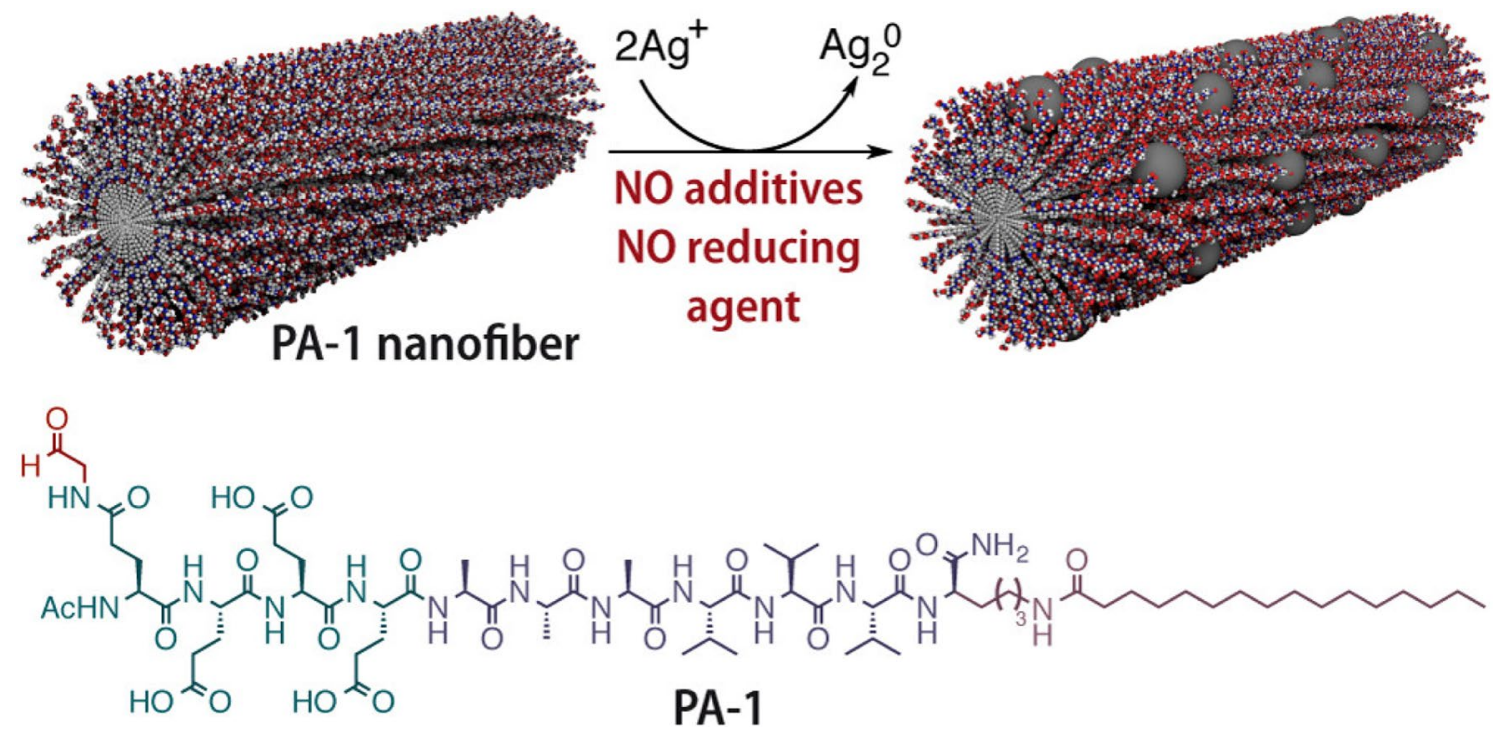

Fig. 9 Formation of silver nanoparticles over a PA nanofiber for potential antibacterial effects [reprinted with permission from (Pazos et al. 2016)] 
multiple rounds of treatment. This was attributed to higher AMP release dependent on the stimuli.

Peptide nanofibers can be an alternative for incorporating therapeutic nanoparticles (silver nanoparticles) for the development of hydrogels with potent antibacterial functions. Pazos et al. developed peptide nanofibers for the nucleation and growth of ordered arrays of silver nanostructures at fairly regular distances along the length of the filamentous organic assemblies as presented in Fig. 9 (Pazos et al. 2016). This nano-assembly exhibited antibacterial activity against $E$. coli and possessed minimal toxicity towards eukaryotic cells, suggesting the possibility of hydrogel development for the effective delivery of silver nanoparticles. Although the peptide used in this study was not an AMP, a similar approach can be used with AMPs so that dual antibacterial effects of AMP and silver nanoparticles can be combined for synergistic antibacterial effects.

In another study by Yu et al., supramolecular assemblies of heterogeneous mesoporous silica nanoparticles were prepared for the co-delivery of AMPs (melittin) and antibiotic (ofloxacin) to synergistically eradicate the pathogenic biofilms (Fig. 10) (Yu et al. 2020). The nano-assembly was composed of mesoporous silica nanoparticles (MSNs) with large pores capped by $\beta$-cyclodextrin-modified polyethyleneimine as host MSNs and adamantine-decorated MSNs containing a magnetic core capped by cucurbit[6] uril as guest MSNs. The assembly released both the AMP and antibiotic with high efficiency based on the stimulus from pathogens along with heating by an alternating magnetic field. The $P$. aeruginosa biofilm eradication of the assembly system was much higher compared to free drugs or unattached MSNs and displayed non-toxicity to mammalian cells. In vivo implantation further eradicated the pathogenic biofilms of $P$. aeruginosa from implants and prevented inflammation and host tissue damage.

\section{Conclusion}

Nanomedicine-based AMP delivery is an emerging concept being investigated for the effective treatment of bacterial infections. Different nanocarrier systems have been developed for the delivery of a plethora of AMPs targeting different bacterial strains (sensitive or resistant). The published literature presents metallic nanoparticles, lipid nanoparticles, and polymeric nanoparticles as potential carriers for AMP delivery in addition to their inherent antimicrobial effects. Nanomedicine-based AMP delivery presents several advantages including the enhancement of peptide stability and efficacy, controlled or sustained release properties, targetability, and synergistic antimicrobial effects. However, the shortcomings including nanocarrier aggregations, toxicity, and non-biodegradability pose a challenge to the widespread use of nanomedicine-based AMP delivery.

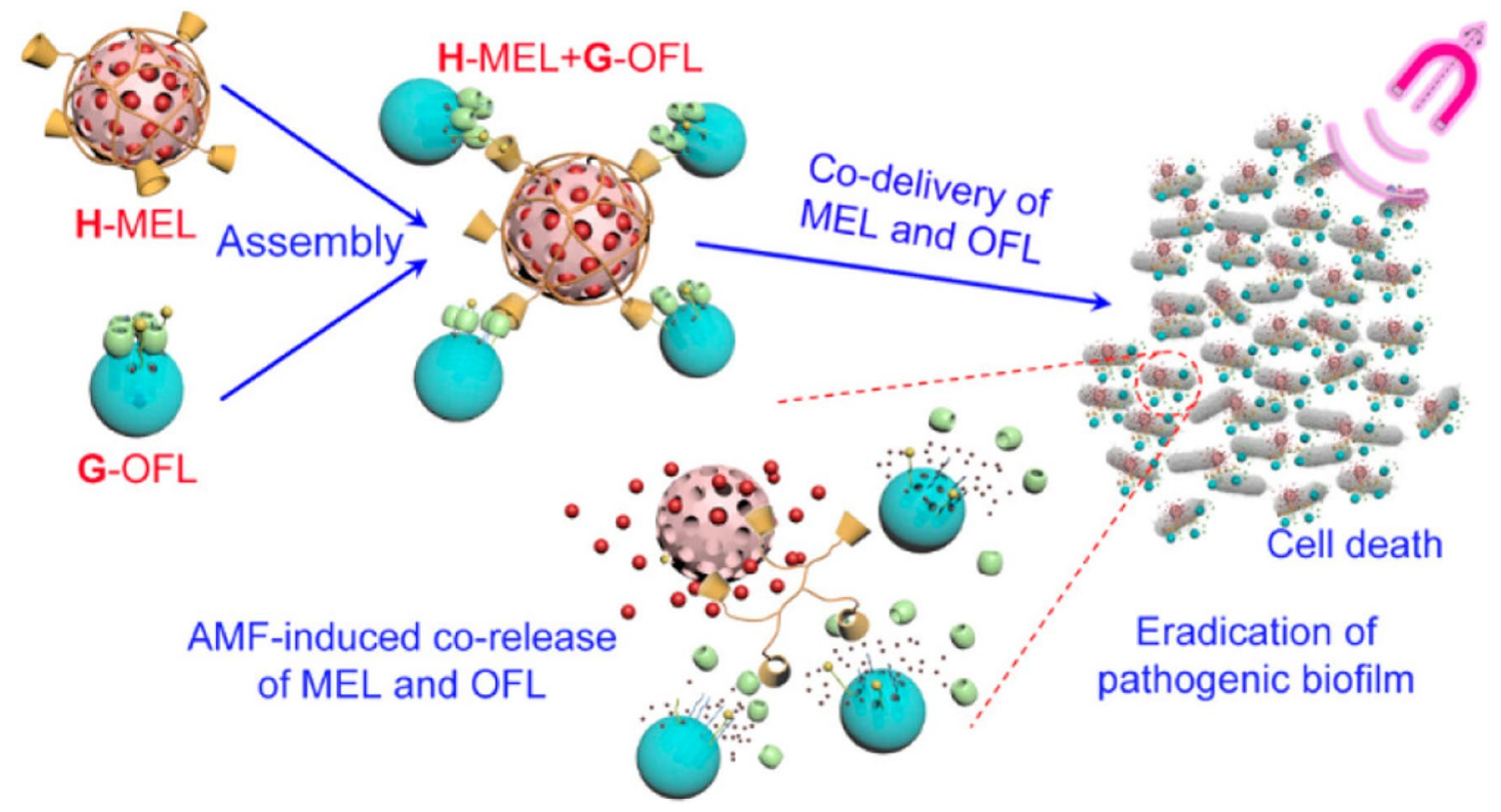

Fig. 10 Schematic representation of the supramolecular assemblies of heterogeneous mesoporous silica nanoparticles to co-deliver antimicrobial peptides and antibiotics for synergistic eradication of pathogenic biofilms [mesoporous silica nanoparticles (MSNs) with large pores (MSNLP); $\beta$-cyclodextrin ( $\beta$-CD)-modified polyethylenimine (PEICD) and adamantane (ADA)-decorated MSNs containing a mag- netic core (MagNP@MSNA) capped by curcurbit[6]uril (CB[6]); host MSNs (H, MSNLP@PEICD); guest MSNs (G, MagNP@ MSNA-CB[6]); melittin (MEL); ofloxacin (OFL); the drug-loading $\mathrm{H}+\mathrm{G}$ coassemblies (H-MEL $+\mathrm{G}-\mathrm{OFL}$ ); alternating magnetic field (AMF)] [reprinted with permission from (Yu et al. 2020)] 
Hybrid formulations of AMP loaded nanoparticles are thus required to enhance their advantages and mitigate the shortcomings. There are very few hybrid systems developed so far for this purpose. The AMP loaded nanoparticles for intravenous delivery can be covered with PEG or other biodegradable polymers that can prevent the interactions with blood components and reduce their toxicity. Furthermore, suitable ligands can be conjugated on the nanoparticle surface to target them to the infected sites. The orally delivered AMP loaded nanoparticles can be covered with polymers or coating that are microenvironment responsive (e.g. $\mathrm{pH}$ sensitive) so that the nanoparticles are uncovered at the target site to exhibit potent antimicrobial effects. The topical application still remains the most challenging strategy for nanomedicine-based AMP delivery. The bioadhesivity of nanoparticles is limited, which allows shorter contact time for the AMP loaded nanoparticles following topical application (e.g. for the treatment of chronic infected wounds) and limits their therapeutic efficacy. Furthermore, the toxicity of nanoparticles (e.g. metallic nanoparticles) in the wound site should be considered, and a controlled nanoparticle release would provide an ideal situation. Considering these facts, the development of hybrid systems composed of AMP loaded nanoparticles embedded within cream, gel, or ointment formulation for the topical application would be advantageous. Furthermore, the development of stimuli- or microenvironment-responsive hybrid systems could enhance the antimicrobial activity of the system. A combination of AMP loaded nanoparticles along with other nanoparticles (e.g. gold nanoparticles for the thermoresponsive property following NIR irradiation) or $\mathrm{pH} / \mathrm{enzyme}$ responsive AMP release systems can provide controlled and targeted AMP release. Furthermore, the combination of peptide assemblies and AMP loaded nanoparticles can be utilized for the development of nanomedicine-based formulations for AMP delivery.

Different nanoparticle systems possess their unique properties and functions suitable for AMP delivery. It is important to enhance the advantages of such systems by modifying the nanoparticles for effective AMP loading and delivery, and resolve the issues related to nanoparticle stability, toxicity, and resulting therapeutic efficacy. There are no marketed formulations of AMP loaded nanoparticles, to date. Therefore, rigorous studies for both the AMP loaded nanoparticle preparation and characterization, and detailed evaluations of their in vitro and in vivo antimicrobial effects and toxicities, are essential. Such studies can eventually lead to the development of a smart, microenvironment/stimuli-responsive and safe nanomedicine-based AMP delivery approach for the effective treatment of bacterial infections.
Acknowledgements The study was supported by the Research Program on Better Health and Quality of Life (BEDREHELSE) from the Research Council of Norway (\# 273646).

Funding Open access funding provided by University of Oslo (incl Oslo University Hospital).

\section{Compliance with ethical standards}

Conflict of interest All authors (R.K. Thapa, D.B. Diep, and H.H. Tønnesen) declare that they have no conflict of interest.

Research involving human and animal rights This article does not contain any studies with human and animal subjects performed by any of the authors.

Open Access This article is licensed under a Creative Commons Attribution 4.0 International License, which permits use, sharing, adaptation, distribution and reproduction in any medium or format, as long as you give appropriate credit to the original author(s) and the source, provide a link to the Creative Commons licence, and indicate if changes were made. The images or other third party material in this article are included in the article's Creative Commons licence, unless indicated otherwise in a credit line to the material. If material is not included in the article's Creative Commons licence and your intended use is not permitted by statutory regulation or exceeds the permitted use, you will need to obtain permission directly from the copyright holder. To view a copy of this licence, visit http://creativecommons.org/licenses/by/4.0/.

\section{References}

Aida KL, Kreling PF, Caiaffa KS et al (2018) Antimicrobial peptideloaded liquid crystalline precursor bioadhesive system for the prevention of dental caries. Int J Nanomed 13:3081-3091

Akbarzadeh A, Rezaei-Sadabady R, Davaran S et al (2013) Liposome: classification, preparation, and applications. Nanoscale Res Lett 8:102-102

Akhavan O, Abdolahad M, Abdi Y et al (2011) Silver nanoparticles within vertically aligned multi-wall carbon nanotubes with open tips for antibacterial purposes. J Mater Chem 21:387-393

Alipour M, Halwani M, Omri A et al (2008) Antimicrobial effectiveness of liposomal polymyxin B against resistant Gram-negative bacterial strains. Int J Pharm 355:293-298

Almaaytah A, Mohammed GK, Abualhaijaa A et al (2017) Development of novel ultrashort antimicrobial peptide nanoparticles with potent antimicrobial and antibiofilm activities against multidrug-resistant bacteria. Drug Des Dev Ther 11:3159-3170

Almeida AJ, Souto E (2007) Solid lipid nanoparticles as a drug delivery system for peptides and proteins. Adv Drug Deliv Rev 59:478-490

Amar-Yuli I, Wachtel E, Shoshan EB et al (2007) Hexosome and hexagonal phases mediated by hydration and polymeric stabilizer. Langmuir 23:3637-3645

Anselmo AC, Mitragotri S (2016) Nanoparticles in the clinic. Bioeng Transl Med 1:10-29

Arvizo R, Bhattacharya R, Mukherjee P (2010) Gold nanoparticles: opportunities and challenges in nanomedicine. Expert Opin Drug Deliv 7:753-763

Azizi-Lalabadi M, Ehsani A, Divband B et al (2019) Antimicrobial activity of titanium dioxide and zinc oxide nanoparticles 
supported in 4A zeolite and evaluation the morphological characteristic. Sci Rep 9:17439

Bai Y, Park IS, Lee SJ et al (2011) Aqueous dispersion of surfactantmodified multiwalled carbon nanotubes and their application as an antibacterial agent. Carbon 49:3663-3671

Bals R (2000) Epithelial antimicrobial peptides in host defense against infection. Respir Res 1:5

Band VI, Weiss DS (2015) Mechanisms of antimicrobial peptide resistance in gram-negative bacteria. Antibiotics (Basel) 4:18-41

Baptista PV, Mccusker MP, Carvalho A et al (2018) Nano-strategies to fight multidrug resistant bacteria-"A battle of the titans". Front Microbiol 9:1441-1441

Barenholz Y (2012) Doxil@—the first FDA-approved nano-drug: Lessons learned. J Control Release 160:117-134

Battaglia L, Ugazio E (2019) Lipid nano- and microparticles: an overview of patent-related research. J Nanomater 2019:2834941

Becker ML, Liu J, Wooley KL (2005) Functionalized micellar assemblies prepared via block copolymers synthesized by living free radical polymerization upon peptide-loaded resins. Biomacromol 6:220-228

Becker Peres L, Becker Peres L, De Araújo PHH et al (2016) Solid lipid nanoparticles for encapsulation of hydrophilic drugs by an organic solvent free double emulsion technique. Colloids Surf B Biointerfaces 140:317-323

Begines B, Ortiz T, Pérez-Aranda M et al (2020) Polymeric nanoparticles for drug delivery: recent developments and future prospects. Nanomaterials (Basel) 10:1403

Beloqui A, Solinís M, Rodríguez-Gascón A et al (2016) Nanostructured lipid carriers: promising drug delivery systems for future clinics. Nanomedicine 12:143-161

Bernegossi J, Calixto GM, Sanches PR et al (2015) Peptide KSL-Wloaded mucoadhesive liquid crystalline vehicle as an alternative treatment for multispecies oral biofilm. Molecules 21:E37

Bharathala S, Sharma P (2019) Biomedical applications of nanoparticles. In: Singh S, Maurya PK (eds) Nanotechnology in modern animal biotechnology. Elsevier, Amsterdam, pp 113-132

Boge L, Bysell H, Ringstad L et al (2016) Lipid-based liquid crystals as carriers for antimicrobial peptides: phase behavior and antimicrobial effect. Langmuir 32:4217-4228

Boge L, Västberg A, Umerska A et al (2018) Freeze-dried and rehydrated liquid crystalline nanoparticles stabilized with disaccharides for drug-delivery of the plectasin derivative AP114 antimicrobial peptide. J Colloid Interface Sci 522:126-135

Brahmachari S, Das D, Shome A et al (2011) Single-walled nanotube/amphiphile hybrids for efficacious protein delivery: rational modification of dispersing agents. Angew Chem Int Ed Engl 50:11243-11247

Brahmachari S, Mandal SK, Das PK (2014) Fabrication of SWCNTAg nanoparticle hybrid included self-assemblies for antibacterial applications. PLoS ONE 9:e106775

Braun K, Pochert A, Lindén M et al (2016) Membrane interactions of mesoporous silica nanoparticles as carriers of antimicrobial peptides. J Colloid Interface Sci 475:161-170

Cantor S, Vargas L, Rojas AO et al (2019) Evaluation of the antimicrobial activity of cationic peptides loaded in surface-modified nanoliposomes against foodborne bacteria. Int J Mol Sci 20:680

Casciaro B, Moros M, Rivera-Fernández S et al (2017) Gold-nanoparticles coated with the antimicrobial peptide esculentin-1a(1-21) $\mathrm{NH} 2$ as a reliable strategy for antipseudomonal drugs. Acta Biomater 47:170-181

Cavalieri F, Tortora M, Stringaro A et al (2014) Nanomedicines for antimicrobial interventions. J Hosp Infect 88:183-190

Cerchiara T, Abruzzo A, Di Cagno M et al (2015) Chitosan based micro- and nanoparticles for colon-targeted delivery of vancomycin prepared by alternative processing methods. Eur J Pharm Biopharm 92:112-119

Chamundeeswari M, Sobhana SSL, Jacob JP et al (2010) Preparation, characterization and evaluation of a biopolymeric gold nanocomposite with antimicrobial activity. Biotechnol Appl Biochem 55:29-35

Chaudhari AA, Jasper SL, Dosunmu E et al (2015) Novel pegylated silver coated carbon nanotubes kill Salmonella but they are nontoxic to eukaryotic cells. J Nanobiotechnol 13:23

Chaudhari AA, Ashmore DA, Nath SD et al (2016) A novel covalent approach to bio-conjugate silver coated single walled carbon nanotubes with antimicrobial peptide. J Nanobiotechnol 14:58

Cheeseman S, Christofferson AJ, Kariuki R et al (2020) Antimicrobial metal nanomaterials: from passive to stimuli-activated applications. Adv Sci 7:1902913

Chen W-Y, Chang H-Y, Lu J-K et al (2015) Self-Assembly of antimicrobial peptides on gold nanodots: against multidrug-resistant bacteria and wound-healing application. Adv Funct Mater 25:7189-7199

Cruz J, Flórez J, Torres R et al (2017) Antimicrobial activity of a new synthetic peptide loaded in polylactic acid or poly(lacticco-glycolic) acid nanoparticles against Pseudomonas aeruginosa, Escherichia coliO157:H7 and methicillin resistant Staphylococcus aureus (MRSA). Nanotechnology 28:135102

Da Silva IM, Boelter JF, Da Silveira NP et al (2014) Phosphatidylcholine nanovesicles coated with chitosan or chondroitin sulfate as novel devices for bacteriocin delivery. J Nanopart Res 16:2479

De Leeuw J, De Vijlder HC, Bjerring P et al (2009) Liposomes in dermatology today. J Eur Acad Dermatol Venereol 23:505-516

Dierking I, Al-Zangana S (2017) Lyotropic liquid crystal phases from anisotropic nanomaterials. Nanomaterials (Basel) 7:305

Długosz O, Szostak K, Staroń A et al (2020) Methods for reducing the toxicity of metal and metal oxide NPs as biomedicine. Materials (Basel) 13:279

Doktorovova S, Souto EB, Silva AM (2014) Nanotoxicology applied to solid lipid nanoparticles and nanostructured lipid carriers-a systematic review of in vitro data. Eur J Pharm Biopharm 87:1-18

Doktorovová S, Kovačević AB, Garcia ML et al (2016) Preclinical safety of solid lipid nanoparticles and nanostructured lipid carriers: current evidence from in vitro and in vivo evaluation. Eur J Pharm Biopharm 108:235-252

Durán N, Durán M, De Jesus MB et al (2016) Silver nanoparticles: a new view on mechanistic aspects on antimicrobial activity. Nanomedicine 12:789-799

Dutta P, Das S (2016) Mammalian antimicrobial peptides: promising therapeutic targets against infection and chronic inflammation. Curr Top Med Chem 16:99-129

Epand RM, Epand RF (2009) Lipid domains in bacterial membranes and the action of antimicrobial agents. Biochim Biophys Acta 1788:289-294

Fam SY, Chee CF, Yong CY et al (2020) Stealth coating of nanoparticles in drug-delivery systems. Nanomaterials (Basel) 10:787

Faya M, Hazzah HA, Omolo CA et al (2020) Novel formulation of antimicrobial peptides enhances antimicrobial activity against methicillin-resistant Staphylococcus aureus (MRSA). Amino Acids 52:1439-1457

Fitzpatrick MC, Bauch CT, Townsend JP et al (2019) Modelling microbial infection to address global health challenges. Nat Microbiol 4:1612-1619

Fraga S, Brandão A, Soares ME et al (2014) Short- and long-term distribution and toxicity of gold nanoparticles in the rat after a single-dose intravenous administration. Nanomedicine 10:1757-1766

Fredenberg S, Wahlgren M, Reslow M et al (2011) The mechanisms of drug release in poly(lactic-co-glycolic acid)-based drug delivery systems-a review. Int J Pharm 415:34-52 
Fumakia M, Ho EA (2016) Nanoparticles encapsulated with LL37 and Serpin A1 promotes wound healing and synergistically enhances antibacterial activity. Mol Pharm 13:2318-2331

Ganesan P, Narayanasamy D (2017) Lipid nanoparticles: different preparation techniques, characterization, hurdles, and strategies for the production of solid lipid nanoparticles and nanostructured lipid carriers for oral drug delivery. Sustain Chem Pharm 6:37-56

Garcia-Orue I, Gainza G, Girbau C et al (2016) LL37 loaded nanostructured lipid carriers (NLC): a new strategy for the topical treatment of chronic wounds. Eur J Pharm Biopharm 108:310-316

García-Gallego S, Franci G, Falanga A et al (2017) Function oriented molecular design: dendrimers as novel antimicrobials. Molecules 22:1581

García-Pinel B, Porras-Alcalá C, Ortega-Rodríguez A et al (2019) Lipid-based nanoparticles: application and recent advances in cancer treatment. Nanomaterials (Basel) 9:638

Gebelein CG, Carraher CE (1985) Bioactive polymeric systems: an overview. Springer, New York, pp 1-15

Ghasemiyeh P, Mohammadi-Samani S (2018) Solid lipid nanoparticles and nanostructured lipid carriers as novel drug delivery systems: applications, advantages and disadvantages. Res Pharm Sci 13:288-303

Gide M, Nimmagadda A, Su M et al (2018) Nano-sized lipidated dendrimers as potent and broad-spectrum antibacterial agents. Macromol Rapid Commun 39:1800622

Giuliani A, Pirri G, Nicoletto SF (2007) Antimicrobial peptides: an overview of a promising class of therapeutics. Cent Eur J Biol 2:1-33

Gomaa AI, Martinent C, Hammami R et al (2017) Dual coating of liposomes as encapsulating matrix of antimicrobial peptides: development and characterization. Front Chem 5:103

Gómez-Sequeda N, Ruiz J, Ortiz C et al (2020) Potent and specific antibacterial activity against Escherichia coli O157:H7 and methicillin resistant Staphylococcus aureus (MRSA) of G17 and G19 peptides encapsulated into poly-lactic-co-glycolic acid (PLGA) nanoparticles. Antibiotics (Basel) 9:384

Gontsarik M, Yaghmur A, Salentinig S (2021) Dispersed liquid crystals as $\mathrm{pH}$-adjustable antimicrobial peptide nanocarriers. J Colloid Interface Sci 583:672-682

Gounani Z, Asadollahi MA, Meyer RL et al (2018) Loading of polymyxin B onto anionic mesoporous silica nanoparticles retains antibacterial activity and enhances biocompatibility. Int J Pharm 537:148-161

Grzelczak M, Vermant J, Furst EM et al (2010) Directed self-assembly of nanoparticles. ACS Nano 4:3591-3605

Gu H, Ho PL, Tong E et al (2003) Presenting vancomycin on nanoparticles to enhance antimicrobial activities. Nano Lett 3:1261-1263

Gustafson HH, Holt-Casper D, Grainger DW et al (2015) Nanoparticle uptake: the phagocyte problem. Nano Today 10:487-510

Haynie SL, Crum GA, Doele BA (1995) Antimicrobial activities of amphiphilic peptides covalently bonded to a water-insoluble resin. Antimicrob Agents Chemother 39:301-307

Hu X, Zhang Y, Ding T et al (2020) Multifunctional gold nanoparticles: a novel nanomaterial for various medical applications and biological activities. Front Bioeng Biotechnol 8:990

Huang Y, Gui S (2018) Factors affecting the structure of lyotropic liquid crystals and the correlation between structure and drug diffusion. RSC Adv 8:6978-6987

Håkansson J, Ringstad L, Umerska A et al (2019) Characterization of the in vitro, ex vivo, and in vivo efficacy of the antimicrobial peptide DPK-060 used for topical treatment. Front Cell Infect Microbiol 9:174

Iravani S, Korbekandi H, Mirmohammadi SV et al (2014) Synthesis of silver nanoparticles: chemical, physical and biological methods. Res Pharm Sci 9:385-406
Jambhrunkar S, Qu Z, Popat A et al (2014) Modulating in vitro release and solubility of griseofulvin using functionalized mesoporous silica nanoparticles. J Colloid Interface Sci 434:218-225

Jamkhande PG, Ghule NW, Bamer AH, Kalaskar MG (2019) Metal nanoparticles synthesis: an overview on methods of preparation, advantages and disadvantages, and applications. J Drug Deliv Sci Technol 53:101174

Kasongo KW, Müller RH, Walker RB (2012) The use of hot and cold high pressure homogenization to enhance the loading capacity and encapsulation efficiency of nanostructured lipid carriers for the hydrophilic antiretroviral drug, didanosine for potential administration to paediatric patients. Pharm Dev Technol $17: 353-362$

Khandare J, Minko T (2006) Polymer-drug conjugates: progress in polymeric prodrugs. Prog Polym Sci 31:359-397

Lallo Da Silva B, Abuçafy MP, Berbel Manaia E et al (2019) Relationship between structure and antimicrobial activity of zinc oxide nanoparticles: an overview. Int J Nanomed 14:9395-9410

Le C-F, Fang C-M, Sekaran SD (2017) Intracellular targeting mechanisms by antimicrobial peptides. Antimicrob Agents Chemother 61:e02340-e12316

Lee SH, Jun B-H (2019) Silver nanoparticles: synthesis and application for nanomedicine. Int J Mol Sci 20:865

Lewies A, Wentzel JF, Jordaan A et al (2017) Interactions of the antimicrobial peptide nisin $\mathrm{Z}$ with conventional antibiotics and the use of nanostructured lipid carriers to enhance antimicrobial activity. Int J Pharm 526:244-253

Lin C-C, Yeh Y-C, Yang C-Y et al (2002) Selective binding of mannose-encapsulated gold nanoparticles to type 1 pili in Escherichia coli. J Am Chem Soc 124:3508-3509

Liu L, Yang J, Xie J et al (2013) The potent antimicrobial properties of cell penetrating peptide-conjugated silver nanoparticles with excellent selectivity for Gram-positive bacteria over erythrocytes. Nanoscale 5:3834-3840

López-Abarrategui C, Alba A, Silva ON et al (2012) Functional characterization of a synthetic hydrophilic antifungal peptide derived from the marine snail Cenchritis muricatus. Biochimie 94:968-974

Madeira C, Mendes RD, Ribeiro SC et al (2010) Nonviral gene delivery to mesenchymal stem cells using cationic liposomes for gene and cell therapy. J Biomed Biotechnol 2010:735349-735349

Madheswaran T, Kandasamy M, Bose RJC et al (2019) Current potential and challenges in the advances of liquid crystalline nanoparticles as drug delivery systems. Drug Discov Today 24:1405-1412

Magana M, Pushpanathan M, Santos AL et al (2020) The value of antimicrobial peptides in the age of resistance. Lancet Infect Dis 20:e216-e230

Makhathini SS, Kalhapure RS, Jadhav M et al (2019) Novel twochain fatty acid-based lipids for development of vancomycin $\mathrm{pH}$-responsive liposomes against Staphylococcus aureus and methicillin-resistant Staphylococcus aureus (MRSA). J Drug Target 27:1094-1107

Mccarthy TD, Karellas P, Henderson SA et al (2005) Dendrimers as drugs: discovery and preclinical and clinical development of dendrimer-based microbicides for HIV and STI prevention. Mol Pharm 2:312-318

Mei L, Lu Z, Zhang W et al (2013) Bioconjugated nanoparticles for attachment and penetration into pathogenic bacteria. Biomaterials $34: 10328-10337$

Meikle TG, Zabara A, Waddington LJ et al (2017) Incorporation of antimicrobial peptides in nanostructured lipid membrane mimetic bilayer cubosomes. Colloids Surf B Biointerfaces 152:143-151

Mohamed MM, Fouad SA, Elshoky HA et al (2017) Antibacterial effect of gold nanoparticles against Corynebacterium pseudotuberculosis. Int J Vet Sci Med 5:23-29 
Mohammed Fayaz A, Girilal M, Mahdy SA et al (2011) Vancomycin bound biogenic gold nanoparticles: a different perspective for development of anti VRSA agents. Process Biochem 46:636-641

Monteiro N, Martins A, Reis RL et al (2014) Liposomes in tissue engineering and regenerative medicine. J R Soc Interface 11:20140459-20140459

Mookherjee N, Hancock REW (2007) Cationic host defence peptides: Innate immune regulatory peptides as a novel approach for treating infections. Cell Mol Life Sci 64:922

Moorcroft SCT, Roach L, Jayne DG et al (2020) Nanoparticle-loaded hydrogel for the light-activated release and photothermal enhancement of antimicrobial peptides. ACS Appl Mater Interfaces 12:24544-24554

Morales-Avila E, Ferro-Flores G, Ocampo-García BE et al (2017) Antibacterial efficacy of gold and silver nanoparticles functionalized with the ubiquicidin (29-41) antimicrobial peptide. J Nanomater 2017:5831959

Mortazavian H, Foster LL, Bhat R et al (2018) Decoupling the functional roles of cationic and hydrophobic groups in the antimicrobial and hemolytic activities of methacrylate random copolymers. Biomacromol 19:4370-4378

Mukherjee S, Ray S, Thakur RS (2009) Solid lipid nanoparticles: a modern formulation approach in drug delivery system. Indian $\mathbf{J}$ Pharm Sci 71:349-358

Pal I, Brahmkhatri VP, Bera S et al (2016) Enhanced stability and activity of an antimicrobial peptide in conjugation with silver nanoparticle. J Colloid Interface Sci 483:385-393

Pal I, Bhattacharyya D, Kar RK et al (2019) A peptide-nanoparticle system with improved efficacy against multidrug resistant bacteria. Sci Rep 9:4485

Palmieri G, Tatè R, Gogliettino M et al (2018) Small synthetic peptides bioconjugated to hybrid gold nanoparticles destroy potentially deadly bacteria at submicromolar concentrations. Bioconjug Chem 29:3877-3885

Pazos E, Sleep E, Rubert Pérez CM et al (2016) Nucleation and growth of ordered arrays of silver nanoparticles on peptide nanofibers: hybrid nanostructures with antimicrobial properties. J Am Chem Soc 138:5507-5510

Peng L-H, Huang Y-F, Zhang C-Z et al (2016) Integration of antimicrobial peptides with gold nanoparticles as unique non-viral vectors for gene delivery to mesenchymal stem cells with antibacterial activity. Biomaterials 103:137-149

Pinto Reis C, Neufeld RJ, Ribeiro AJ et al (2006) Nanoencapsulation I. Methods for preparation of drug-loaded polymeric nanoparticles. Nanomedicine 2:8-21

Piotrowska U, Sobczak M (2014) Enzymatic polymerization of cyclic monomers in ionic liquids as a prospective synthesis method for polyesters used in drug delivery systems. Molecules 20:1-23

Piras AM, Maisetta G, Sandreschi S et al (2015) Chitosan nanoparticles loaded with the antimicrobial peptide temporin B exert a long-term antibacterial activity in vitro against clinical isolates of Staphylococcus epidermidis. Front Microbiol 6:372-372

Pompilio A, Geminiani C, Mantini P et al (2018) Peptide dendrimers as "lead compounds" for the treatment of chronic lung infections by Pseudomonas aeruginosa in cystic fibrosis patients: in vitro and in vivo studies. Infect Drug Resist 11:1767-1782

Pranantyo D, Xu LQ, Kang ET et al (2016) Conjugation of polyphosphoester and antimicrobial peptide for enhanced bactericidal activity and biocompatibility. Biomacromol 17:4037-4044

Puri A, Loomis K, Smith B et al (2009) Lipid-based nanoparticles as pharmaceutical drug carriers: from concepts to clinic. Crit Rev Ther Drug Carrier Syst 26:523-580

Qi G, Li L, Yu F et al (2013) Vancomycin-modified mesoporous silica nanoparticles for selective recognition and killing of pathogenic gram-positive bacteria over macrophage-like cells. ACS Appl Mater Interfaces 5:10874-10881

Rai A, Pinto S, Velho TR et al (2016) One-step synthesis of highdensity peptide-conjugated gold nanoparticles with antimicrobial efficacy in a systemic infection model. Biomaterials 85:99-110

Rajchakit U, Sarojini V (2017) Recent developments in antimicrobial-peptide-conjugated gold nanoparticles. Bioconjug Chem 28:2673-2686

Riley MA, Wertz JE (2002) Bacteriocins: evolution, ecology, and application. Annu Rev Microbiol 56:117-137

Ringsdorf H (1975) Structure and properties of pharmacologically active polymers. J Polym Sci Polym Symp 51:135-153

Roccatano D, Sarukhanyan E, Zangi R (2017) Adsorption mechanism of an antimicrobial peptide on carbonaceous surfaces: a molecular dynamics study. J Chem Phys 146:074703

Rosemary MJ, Maclaren I, Pradeep T (2006) Investigations of the antibacterial properties of ciprofloxacin@SiO2. Langmuir 22:10125-10129

Ruden S, Hilpert K, Berditsch M et al (2009) Synergistic interaction between silver nanoparticles and membrane-permeabilizing antimicrobial peptides. Antimicrob Agents Chemother 53:3538-3540

Sánchez-López E, Gomes D, Esteruelas G et al (2020) Metal-based nanoparticles as antimicrobial agents: an overview. Nanomaterials (Basel) 10:292

Scorciapino MA, Serra I, Manzo G et al (2017) Antimicrobial dendrimeric peptides: structure, activity and new therapeutic applications. Int J Mol Sci 18:542

Selvarajan V, Obuobi S, Ee PLR (2020) Silica nanoparticles-A versatile tool for the treatment of bacterial infections. Front Chem 8:602-602

Severino P, Silveira EF, Loureiro K et al (2017) Antimicrobial activity of polymyxin-loaded solid lipid nanoparticles (PLX-SLN): characterization of physicochemical properties and in vitro efficacy. Eur J Pharm Sci 106:177-184

Shaikh S, Nazam N, Rizvi SMD et al (2019) Mechanistic insights into the antimicrobial actions of metallic nanoparticles and their implications for multidrug resistance. Int J Mol Sci 20:2468

Sharma R, Raghav R, Priyanka K et al (2019) Exploiting chitosan and gold nanoparticles for antimycobacterial activity of in silico identified antimicrobial motif of human neutrophil peptide-1. Sci Rep 9:7866-7866

Shen S, Wu Y, Liu Y et al (2017) High drug-loading nanomedicines: progress, current status, and prospects. Int J Nanomed 12:4085-4109

Slepička P, Slepičková Kasálková N, Siegel J et al (2019) Methods of gold and silver nanoparticles preparation. Materials (Basel) 13:1

Sobczak M, Dębek C, Olędzka E et al (2013) Polymeric systems of antimicrobial peptides-strategies and potential applications. Molecules 18:14122-14137

Sobczak M, Kamysz W, Tyszkiewicz W et al (2014) Biodegradable macromolecular conjugates of citropin: synthesis, characterization and in vitro efficiency study. React Funct Polym 83:54-61

Souto EB, Almeida AJ, Müller RH (2007) Lipid nanoparticles (SLN®, NLC( $)$ for cutaneous drug delivery: structure, protection and skin effects. J Biomed Nanotechnol 3:317-331

Tacconelli E, Carrara E, Savoldi A et al (2018) Discovery, research, and development of new antibiotics: the WHO priority list of antibiotic-resistant bacteria and tuberculosis. Lancet Infect Dis 18:318-327

Tenland E, Pochert A, Krishnan N et al (2019) Effective delivery of the anti-mycobacterial peptide NZX in mesoporous silica nanoparticles. PLoS ONE 14:e0212858-e0212858 
Thapa RK, Choi JY, Poudel BK et al (2015) Multilayer-coated liquid crystalline nanoparticles for effective sorafenib delivery to hepatocellular carcinoma. ACS Appl Mater Interfaces 7:20360-20368

Thapa RK, Diep DB, Tønnesen HH (2020) Topical antimicrobial peptide formulations for wound healing: current developments and future prospects. Acta Biomater 103:52-67

Torchilin VP (2005) Recent advances with liposomes as pharmaceutical carriers. Nat Rev Drug Discov 4:145-160

Ulbrich K, Holá K, Šubr V et al (2016) Targeted drug delivery with polymers and magnetic nanoparticles: covalent and noncovalent approaches, release control, and clinical studies. Chem Rev 116:5338-5431

Vardharajula S, Ali SZ, Tiwari PM et al (2012) Functionalized carbon nanotubes: biomedical applications. Int J Nanomed 7:5361-5374

Ventola CL (2015) The antibiotic resistance crisis: part 1: causes and threats. Pharm Ther 40:277-283

Vignoni M, De Alwis WH, Simpson MJ et al (2014) LL37 peptide@ silver nanoparticles: combining the best of the two worlds for skin infection control. Nanoscale 6:5725-5728

Wadhwani P, Heidenreich N, Podeyn B et al (2017) Antibiotic gold: tethering of antimicrobial peptides to gold nanoparticles maintains conformational flexibility of peptides and improves trypsin susceptibility. Biomater Sci 5:817-827

Wang S, Yan C, Zhang X et al (2018) Antimicrobial peptide modification enhances the gene delivery and bactericidal efficiency of gold nanoparticles for accelerating diabetic wound healing. Biomater Sci 6:2757-2772

Weller RB (2009) Nitric oxide-containing nanoparticles as an antimicrobial agent and enhancer of wound healing. J Investig Dermatol 129:2335-2337

Were LM, Bruce BD, Davidson PM et al (2003) Size, stability, and entrapment efficiency of phospholipid nanocapsules containing polypeptide antimicrobials. J Agric Food Chem 51:8073-8079

Xiu Z-M, Zhang Q-B, Puppala HL et al (2012) Negligible particlespecific antibacterial activity of silver nanoparticles. Nano Lett $12: 4271-4275$

Xu C, Yu M, Noonan O et al (2015) Core-cone structured monodispersed mesoporous silica nanoparticles with ultra-large cavity for protein delivery. Small 11:5949-5955
Yang K, Gitter B, Rüger R et al (2011) Antimicrobial peptide-modified liposomes for bacteria targeted delivery of temoporfin in photodynamic antimicrobial chemotherapy. Photochem Photobiol Sci 10:1593-1601

Yang X, Yang M, Pang B et al (2015) Gold Nanomaterials at work in biomedicine. Chem Rev 115:10410-10488

Yeom J-H, Lee B, Kim D et al (2016) Gold nanoparticle-DNA aptamer conjugate-assisted delivery of antimicrobial peptide effectively eliminates intracellular Salmonella enterica serovar Typhimurium. Biomaterials 104:43-51

Yick S, Mai-Prochnow A, Levchenko I et al (2015) The effects of plasma treatment on bacterial biofilm formation on verticallyaligned carbon nanotube arrays. RSC Adv 5:5142-5148

Yin IX, Zhang J, Zhao IS et al (2020) The antibacterial mechanism of silver nanoparticles and its application in dentistry. Int $\mathrm{J}$ Nanomed 15:2555-2562

Yingchoncharoen P, Kalinowski DS, Richardson DR (2016) Lipidbased drug delivery systems in cancer therapy: what is available and what is yet to come. Pharmacol Rev 68:701-787

Yu Q, Deng T, Lin F-C et al (2020) Supramolecular assemblies of heterogeneous mesoporous silica nanoparticles to co-deliver antimicrobial peptides and antibiotics for synergistic eradication of pathogenic biofilms. ACS Nano 14:5926-5937

Zasloff M (2002) Antimicrobial peptides of multicellular organisms. Nature 415:389-395

Zhao G, Chen Y, He Y et al (2019) Succinylated casein-coated peptidemesoporous silica nanoparticles as an antibiotic against intestinal bacterial infection. Biomater Sci 7:2440-2451

Zhu X, Radovic-Moreno AF, Wu J et al (2014) Nanomedicine in the management of microbial infection-overview and perspectives. Nano Today 9:478-498

Publisher's Note Springer Nature remains neutral with regard to jurisdictional claims in published maps and institutional affiliations. 